\title{
A six-dimensional model for supply chain sustainability risk analysis in telecommunication networks: a case study
}

Supply chain sustainability risk analysis

\author{
Keyvan Rezghdeh and Sajjad Shokouhyar \\ Department of Management and Accounting, Shahid Beheshti University, \\ Tehran, Iran
}

Received 14 September 2019 Revised 24 November 2019 1 February 2020

Accepted 6 March 2020

\begin{abstract}
Purpose - The main purpose of the present study was to improve and develop previously proposed models for Iran telecommunication networks. It should be noted that the six-dimensional (6D) sustainability model used in this study will be a useful and comprehensive model for industries. Since, the new dimension of IT along with the five well-known economic, social, environmental, technical and institutional aspects of organizations is considered to have great impacts on supply chain sustainability; the proposed framework can be practical.

Design/methodology/approach - According to the related literature review, there are two research streams in supply chain management. The first stream is exploratory research, seeking out conceptual discussions in this area. The second one is associated with mathematical models and techniques, aiming to set decisionmaking rules in this regard (Agrell et al., 2004). In this study, evaluation was performed using the FMEA method as an analytical technique based on the principle of pre-occurrence prevention to identify potential failure factors in sensitive systems (Mohammadfam and Kianfari, 2008).

Findings - After identifying the risks and causes of the incidence and effects and consequences of risks, preventive and risk control measures and advisory strategies were presented. Customers with $45.76 \%$ share in critical risks are threatening to maintain supply chain in these companies. During this study, it was found that $33.9 \%$ of the main source of supply chain critical risks was customers, constituting $45.76 \%$ of such risks, accompanied by organization, having a $38.88 \%$ share of critical risk generation. The study findings also revealed that $33.9 \%$ of critical risks were mainly (equally) related to economic and technical aspects of supply chain sustainability in telecommunication networks. Moreover, as a newly-introduced sixth dimension, IT represented $10.17 \%$ of critical risks threatening supply chain sustainability in such networks. Critical risks are mainly related to the economic and technical aspects (equally) with the sustainability of the telecommunication networks supply chain. Also, as a new finding and the sixth dimension, $10.17 \%$ of the critical risks that threaten the sustainability of the telecommunication networks supply chain have the information technology dimension.

Originality/value - The internet and fixed and mobile data services are provided by several private companies in Iran, which are relatively similar in terms of their supply chains. In order to manage the sustainability of Iran's telecommunication supply chain, telecommunication networks affiliated to Iran Telecommunication Company (ITC), operating in the field of data and internet services and fixed telephone were selected in 31 provinces. The intended networks were also providing an important part of the country's needs including Mobile Telecommunication Company of Iran, a subsidiary of Iran's telecommunication networks, as one of the top companies in this industry. Accordingly, all the networks studied in this study needed to be identified with regard to communication sustainability risks, since they provide management
\end{abstract}

(C) Keyvan Rezghdeh and Sajjad Shokouhyar. Published in Modern Supply Chain Research and Applications. Published by Emerald Publishing Limited. This article is published under the Creative Commons Attribution (CC BY 4.0) license. Anyone may reproduce, distribute, translate and create derivative works of this article (for both commercial and non-commercial purposes), subject to full attribution to the original publication and authors. The full terms of this license may be seen at http:// creativecommons.org/licences/by/4.0/legalcode

The authors express their sincere gratitude to managers and experts of telecommunication networks in all provinces of Iran for their participation in the interviews used in this study.

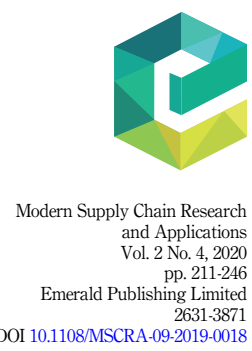


MSCRA

2,4

solutions to each other by segregating risks. In this study, 68 managers and 72 experts participated in different work teams of telecommunication networks.

Keywords Six-dimensional model, Supply chain, Sustainability, FMEA, Risk, Telecommunication networks Paper type Case study

\section{Introduction}

Supply chain sustainability, material flow management, information and capital management as well as inter-company collaboration across supply chain integrated with goals throughout all three dimensions (i.e. economic, environmental and social) of sustainable development can meet the needs of customers and stakeholders. Within a sustainable supply chain, members apply social and environmental criteria to stay in the chain, and at the same time, competitiveness is also expected to be maintained by responding to customer needs and related economic criteria (Seuring and Muller, 2008).

As Iran has the largest telecommunication networks in the Middle East, the rapid growth of this industry is significant. Telecommunication networks are among industries that have made great efforts towards sustainable development. Therefore, increasing volume of telecommunication services and fast development of technology in the world has made this industry very competitive (Ahmadi et al., 2008).

Companies operating in Iran's telecommunications industry are facing a number of uncertainties and challenges compared with similar industries in other countries, which have raised many questions in managing supply chain sustainability risk in Iran's telecommunication networks. One of the most important challenges threatening the Iranian telecommunication industry is inadequate infrastructure and equipment in some sectors, resulting in customer service problems (Zand Hesami and Savoji, 2011).

Therefore, supply chain sustainability risks must be properly identified as they affect one or more project objectives if they occur (Nazari et al., 2008).

Using green equipment and technology can be also a powerful competitive tool in this industry. For example, use of end-of-pipe technologies is an investment in pollution control that must be done jointly between telecommunication networks and manufacturers or suppliers (Shokouhyar et al., 2019).

To realize systematization of technical risk management using failure modes and effects analysis (FMEA) method to optimize decision-making process in new product development (NPD), Segismundo and Cauchick Miguel (2008) reported that reduction in the number of projects and test planning loops as well as a decreased number of prototypes were essential to approve product components. In addition, they could have a positive influence on NPD and decision-making process, indicating a better allocation of resources between planned projects.

One of the benefits of the FMEA method is the ability to take actions instead of reactions. In other words, precautions take precedence over corrective actions in this technique, because in the event of an unfortunate accident, most financial resources will be spent on offsetting states and losses (Abdolhamidzadeh and Badri, 2014). The FMEA is also a basic systematic method that:

(1) Identifies defects and faults present in a system, a product, and a process (Abdolhamidzadeh and Badri, 2014).

(2) Acts to eliminate defects and faults by adopting tactics. Therefore, the FMEA can be called one of the best tools for improving quality of products and services in companies.

Other benefits of FMEA may include (Abdolhamidzadeh and Badri, 2014): 
(1) Improving quality

(2) Reducing duplication of works and actions

(3) Increasing product security

(4) Augmenting product confidence

Despite such benefits, some scholars have criticized the rational logic behind the conventional FMEA method. Some of these arguments are as follows (Mirfakhroddini et al., 2012):

(1) RPN assessment does not meet all measurement requirements.

(2) Risk priority in this method neglects relative importance between severity, probability of occurrence and probability of diagnosis.

(3) In this method, risk priority number (RPN) fails to explain effectiveness of correct indicators.

(4) Reasons for using a multiplication operator are unclear and there is a question why other operators are not being used.

Moreover, Pickard et al. (2005) introduced a useful method to simultaneously analyze multiple failures for complex systems. However, they did not indicate which failures needed to be considered and how they could be combined appropriately. The present study extended the work by Pickard et al. through proposing a minimal cut set-based method for assessing the impact of multiple failure modes. In addition, conventional FMEA method was used via addressing problems in an order from the biggest RPN to the smallest ones. However, one disadvantage of this approach was ignoring the fact that three factors (i.e. severity (S), occurrence (O) and detection (D)) (S, O, D) had different weights in a system rather than equality. For example, reasonable weights for factors $\mathrm{S}$ and $\mathrm{O}$ were higher than that of $\mathrm{D}$ for some non-repairable systems.

According to Ningcong Xiao et al. (2011), the FMEA method, could traditionally consider only the impact of single failure on a system. For large and complex systems, assessing multiple failure modes with all possible combinations was thus impractical since there were multiple failures of some components. They also extended the definition of RPN by multiplying it with a weight parameter, characterizing the importance of failure causes within a system. Finally, effectiveness of the method was demonstrated through numerical examples.

Garcia et al. (2005) similarly presented a data envelopment analysis (DEA) approach for determining and ranking indices among failure modes in which typical FMEA parameters were modeled as fuzzy sets. Using this approach, inference rules of if then could be bypassed. The proposed approach was also applied to a typical pressurized water reactor (PWR) auxiliary feed water system and the results were compared with those obtained by means of RPNs, pure fuzzy logic concepts and finally DEA-profiling of severity efficiency approach (APGF). The results demonstrated the potential of the combination of fuzzy logic concepts and DEA for this class of problems.

Also, Schmittner et al. (2014) found that increasingly complex systems could lead to an interweaving of security, safety, availability and reliability concerns. Since most dependability analysis techniques had not included security aspects, a holistic risk model was needed for systems. In their novel approach, basic failure causes, failure modes and failure effects from the FMEA technique were utilized as a template for a vulnerability causeeffect chain, and this method was extended with security, representing a unified model for safety and security cause-effect analysis. As an example, the technique was then applied to a distributed industrial measurement system. 
MSCRA

2,4

214

It should be noted that renewable energy plays a key role in transition towards a lowcarbon economy as well as provision of a secure supply of energy. Geothermal energy is also a versatile source as a form of renewable energy that meets popular demands. Since some geothermal power plants (GPPs) face various failures, a technique is required for team engineering to eliminate or even decrease potential failures. As no specific published record considering the FMEA method applied to GPPs with common failure modes had been found, Feili et al. (2013), in their research, utilized it as convenient technique for determining, classifying and analyzing common failures in typical GPPs. As a result, an appropriate risk scoring of occurrence, detection and severity of failure modes and computation of RPN for detecting high-potential failures was achieved. In order to expedite accuracy and ability to analyze the process, the XFMEA software was correspondingly utilized. Moreover, five major parts of a GPP were studied to propose a suitable approach for developing GPPs and to increase reliability via recommending corrective actions for each failure mode.

Arabian-Hoseynabadi et al. (2010) also used the FMEA method to evaluate the reliability of numerous power generation systems. Accordingly, they applied this approach to a wind turbine (WT) system using a software reliability analysis tool. The quantitative results of the FMEA method and the reliability data from real wind systems and their assemblies were then compared. The results could discuss building relationships that were useful for future WT designs.

Also, Shokouhyar et al., (2017) employed an integrated model based on project management body of knowledge (PMBOK) standard risk management process and risk FMEA (RFMEA) technique to assess risks and claimed this method was useful for quick and accurate prioritization of risks as well as analysis of situations and failure methods.

Saptarshi Mandal and Maiti (2014) also proposed a fuzzy FMEA model to deal with obvious drawbacks of FMEA approaches. Fuzzy numerical approaches based on defuzzification suffered from the disadvantage of providing arbitrary priority ranks of failure modes even when their membership functions overlapped. To overcome this problem, they developed a new method combining the concepts of fuzzy number similarity measurement and probability theory. Measures of similarity were additionally used for failure modes similar to those with risk values.

Moreover, Valinejad and Rahmani (2018) evaluated and analyzed telecommunication supply chain risks from five sustainability dimensions. They used the FMEA method to calculate RPN (in order to identify, analyze and explain reasons for telecommunication sustainability risks) and then investigated supply chain sustainability based on the fivedimensional (5D) sustainability model without considering information technology (IT) as a sustainability dimension that could create a research gap.

The main purpose of the present study was to improve and develop previously proposed models for Iran's telecommunication networks. It should be noted that the six-dimensional (6D) sustainability model used in this study will be a useful and comprehensive model for industries. Since, the new dimension of IT along with the five well-known economic, social, environmental, technical, and institutional aspects of organizations is considered to have great impacts on supply chain sustainability; the proposed framework can be practical.

\section{Literature review}

In this section, the research literature is analyzed in two separate but related categories: (1) sustainability risk management and (2) IT and sustainability.

\subsection{Sustainability risk management}

Technical and institutional aspects have been thus far mentioned in addition to economic, environmental and social dimensions of sustainable development (Iddrisu and 
Bhattacharyya, 2015). Accordingly, the technical dimension includes technical issues of concern and ability of an industry to meet market needs. The institutional dimensions have been also assigned to legal and institutional issues inside and outside an organization, relationships with partners, relationships with governments, political sustainability, foreign policies and so on. Due to high consistency of this classification with the business environment, the sustainable development model was proposed in this study based on these five dimensions. On the other hand, major developments in the business environment, such as business globalization and rapid pace of technological change, have increased competitiveness and management difficulty of organizations in terms of technology, tastes and customer demands. In such a complex environment, organizations need to understand and differentiate between these rising complexities, so risk management is a strong approach in this respect.

According to the Brundtland Commission's definition of sustainable development, sustainability risks involve environmental, social and economic risks (Papadopoulos and Giannakis, 2016). Such risks also encompass greenhouse gas emissions, natural disasters, accidents, energy consumption, packaging wastes and environmental damage caused by logistics and transportation (Papadopoulos and Giannakis, 2016), according to the given reports (United Nations International Trade Agreement on Liability, 2010).

Supply chain sustainability risk management is therefore of utmost important because of the concepts of sustainable development and risk management as well as understanding of the need to safeguard supply chain sustainability and to adopt measures and solutions against supply chain threats (Arabi et al., 2017). The main goal of supply chain risk management (SCRM) is not just cost-saving, rather it can enhance supply chain sustainability through creating values (Giannakis and Papadopoulos, 2016).

It can be generally concluded that what has been addressed as sustainability risk management in the related literature is limited to one aspect of sustainability (mainly, environmental issues) or some aspects of the three mentioned dimensions. In other words, a three-dimensional (3D) sustainable development model has been merely considered. Indeed, no study has so far focused on the 5D sustainable development model for sustainability risk management. Given the increasing importance of technical and institutional debates in today's world, attention to these two aspects in addition to the previously-developed three aspects seems attractive. Therefore, this study attempted to bridge the existing gap by focusing on a 5D approach developed by Valinejad and Rahmani (2018).

Iranian customers' dissatisfaction with low quality and low speed of the Internet and telecommunication services is mainly due to low capacity and quality of telecommunication technology infrastructure (Shokouhyar et al., 2017). Moreover, this industry is always having problems supplying modern technology and equipment for equipment and technology upgrades because of sanctions, as well as political and economic reasons as the main causes (Zand Hesami and Savoji, 2011).

Eneh (2015), in a study of environmental pollution caused by the effects of electromagnetic waves on communication antennas adjacent to residential and training centers in Nigeria, showed that radiation had caused numerous health challenges despite differences in reports. Further research was thus needed on effects of their propagation on telecommunication mast antennas to establish the facts. His study also examined some health impacts of environmental pollution generated by transmission of electromagnetic waves near educational and residential centers in Anguos, Nigeria.

Development of e-commerce depends on its comprehensive policy and infrastructure. Therefore, such policies and infrastructures are an important way to overcome challenges in the field of IT. Consumer care should not be partially resolved. Instead, contractual principles of consumer care must become laws under a specific policy. Iran should not wait to resolve disputes to assess the appropriateness of its policies and rules for dealing with e-commerce

Supply chain sustainability risk analysis 
MSCRA

2,4

216 issues. Instead, it must adapt itself to modern infrastructure in line with technological advances because it is lagging behind in terms of online contracting and consumer care. Policy-making and legislation of a particular law thus depends on effectiveness of e-commerce contracts, which should remove any legal barriers or obstacles to development of e-commerce and create a secure legal environment for consumers. In spite of economic crisis that Iran is currently suffering from, the policy and infrastructure of the e-commerce industry are well-advanced. Accordingly, lack of e-commerce policies and laws are threatening the information and communications technology (ICT) sector (Bagheri et al., 2012).

Given the long-term strategic benefits of a sustainable supply chain, addressing risks and threats to supply chain sustainability is critical. Supply chain risk management is thus regarded as one of the main topics of recent studies in supply chain management (Narasimhan and Talluri, 2009; Gurnani et al., 2011), therefore, the increasing amount of outsourcing in research development process has been emphasized. In this respect, one study had examined risks associated with sustainable supplier selection and order allocation, in which uncertainty and dynamic nature of some parameters had been investigated. It had also highlighted the impact of suppliers on sustainable supply chain performance in communication industry (Shokouhyar et al., 2018).

\subsection{IT and sustainability}

In an article entitled "Assessing the relationship between sustainability and ICT" (Gouvea et al., 2018) predicted the relationship between environmental sustainability, ICT, and human development. According to their findings, ICT and human development had significant and interactive effects on environmental sustainability. There was also a significant relationship between environmental sustainability and ICT. Moreover, human development could play a similar role in which there was a significant relationship between human development and ICT. It could be concluded that part of human development activities included the widespread presence of ICT and its implementation.

While referring to increasing focus of contemporary discussions on ICT and sustainability, Bifulco et al. (2016) examined the relationship between smart city features within the framework proposed by Giffinger et al. (2007) and new technologies as tools and sustainability. In research results, the relationship between ICT and sustainability was emphasized. Specifically, ICT could be described as tools for activating a part of the intelligence process in cities; explicitly mentioned as the role of ICT by Li et al. (2015). Accordingly, the emphasis was on sustainability.

Jeffrey and Funk (2015) in their study entitled "New strategies for reducing carbon emissions and use of resources in transportation" illustrated how fast and growing rate of smartphones, telecommunication systems and other forms of IT had provided solutions for sustainability and how they had raised opportunities in telecommunication and information systems. Discussing the challenges of universities, especially in the field of telecommunication and information systems, this study had concluded that sustainability was an important challenge for universities, governments and companies, and there were alternative ways of resolving sustainability, currently being addressed by the Intergovernmental Panel on Climate Change (IPCC). However, the potential impact of IT on the best design of transportation, logistics, office and home systems; and for the most part, the fact that one of the problems of design stability was sustainability had been ignored (Rezaei et al., 2019).

According to chapter 10 of "Knowledge Management Books in Libraries" entitled "Information technology and knowledge management" (Nazim and Mukherjee, 2013), although there was a hint of use of communication tools and much knowledge-sharing tools (e.g. intranet and enterprise repositories, content management and so on); utilization of academic libraries in India was still in the early stages of implementing these technologies. 
Some of the librarians' roles in the ICT environment included understanding and defining the nature of social media, creating websites or blogs, as well as establishing a user-friendly network interface and content management. Authorities also needed to hire well-versed library staff to implement ICT-based tools, resources, and services. Lack of IT infrastructure and funding had been further identified as major challenges in utilizing IT-based resources and services in previous studies of academic libraries in Kerala (India) by Haneefa (2007).

An article on application of ICT to sustainable growth of small and medium-sized enterprises (SMEs) in the Indian food industry (Singh et al., 2019) had also identified and analyzed key elements of ICT applications for sustainable growth in such companies. In the Indian food sector, lots of efforts had been thus made and the government was required to take the necessary measures to encourage private and foreign investments and to promote providers of IT services and economic policies related to the business environment to improve the competitiveness of food sector in this country. This would help managers deploy efficient ICT programs to effectively integrate SMEs into their food supply chains.

\section{Research gaps, contributions and innovations}

Four segments of telecommunication supply chain as sources of risk generation (i.e. suppliers, organizations, customers and the environment) were carefully studied and the impact of their risks on supply chain sustainability were identified and classified into six dimensions of environmental, social, economic, technical, institutional and IT. With regard to these six dimensions of sustainability and the four layers of the supply chain, a matrix was designed to assign each of the identified risks based on one of the sustainability dimensions to one of the supply chain layers. This matrix was a powerful tool for accurately identifying supply chain vulnerabilities that would help managers and decision-makers to effectively develop risk management strategies. Finally, the proposed method for risk management was evaluated by examining the telecommunication supply chain in Iran.

\section{Risk management}

Risk management is a tool that can create a low-cost mechanism to risk assessment and risk separation using a method by the lowest cost. It also provides alternatives for their management (Giannakis and Papadopoulos, 2016).

In the related literature, several frameworks have been thus far proposed for completing the risk-management process (Hallikas et al., 2002). However, there is a consensus over the following five consecutive phases of risk management: risk identification, risk assessment, risk analysis, risk treatment and risk monitoring as described below (Giannakis and Papadopoulos, 2016).

\subsection{Risk identification}

As the first phase, risk identification is a prerequisite for identifying project risks to have a clear understanding of its objectives, defined in the planning stage of risk management, which is based on the project charter. Once risk management process is completed in the initial stages, one can enter this phase of risk management process, namely, risk identification (Nazari et al., 2008).

\subsection{Quantitative risk assessment}

Quantitative risk assessment is the second phase of risk management process, performed after qualitative assessment stage, on important and priority risks. It should be noted that quantitative risk assessment is not required in risk management process and it can be
Supply chain sustainability risk analysis 
MSCRA

2,4

218

considered as effective responses to risks without doing so solely on the basis of qualitative assessment results. However, in large projects and in cases wherein there is sufficient time and budget, little evaluation can be done in order to obtain an accurate assessment of the overall impact of the risks on projects. Quantitative risk assessment involves use of specific tools that require a large amount of valid and reliable data whose complexity requires major computer and software computations (Nazari et al., 2008).

Today, the most common and comprehensive risk assessment methods include FMEA, what if analysis, process hazard analysis (PHA), hazard and operability study (HAZOP), and fault tree analysis (FTA). Due to the high volume of activities and high potential risks, it is therefore necessary to provide risk assessments with an applied technique and in the shortest time with optimal efficiency (Abdolhamidzadeh and Badri, 2014).

\subsection{Risk analysis}

In the risk analysis phase, the causes of risks and their likely consequences are determined through interviewing with industry experts (Dabiri, 2009).

\subsection{Risk treatment}

With regard to risk treatment, the following four major strategies have been introduced in the research literature:

(1) Avoidance: This strategy seeks to disconnect risk source in order to make risk-taking impossible and to disconnect risk effect, so that it does not affect project objectives if risk occurs (Nazari et al., 2008).

(2) Transfer: The given strategy does not directly change risk, but involves others in managing and taking responsibility for it (Nazari et al., 2008).

(3) Reduction: It refers to making efforts to reduce risk occurrence likelihood or its severity (Giannakis and Papadopoulos, 2016).

(4) Acceptance: It is accepting possible damages (when costs of each risk treatment strategy exceeds possible risk ones) (Shokouhyar et al., 2013).

\subsection{Risk monitoring}

As the final phase, risk monitoring includes continuous examination of effects of strategies for responding to each risk, identifying risks, making required changes in accordance with dynamic nature of risk management, and proposing new solutions (Wu and Blackhurst, 2009).

\section{Case study description}

The Internet and fixed and mobile data services are provided by several private companies in Iran, which are relatively similar in terms of their supply chains. In order to manage the sustainability of Iran's telecommunication supply chain, telecommunication networks affiliated to Iran Telecommunication Company of Iran (ITC), operating in the field of data and Internet services and fixed telephone were selected in 31 provinces. The intended networks were also providing an important part of the country's needs including Mobile Telecommunication Company of Iran, a subsidiary of Iran's telecommunication networks, as one of the top companies in this industry. Accordingly, all the networks studied in this study needed to be identified with regard to communication sustainability risks, since they provide management solutions to each other by segregating risks. In this study, 68 managers and 72 experts participated in different work teams of telecommunication networks. 
With respect to the number of studies in the field of IT and sustainability and the need to focus on supply chain risk management in telecommunication networks, the researchers developed an overall framework by adding a new dimension of IT sustainability to the five previously delineated dimensions in this study. Sustainability and consideration of four dimensions of telecommunication chain as risk generation sources (i.e. suppliers, organization, customers and the environment) and their use for supply chain in Iran's telecommunication networks, felt in previous research as gap, can thus propose a scientific method to manage these risks and also provide managers with supply chain.

In this study, IT as the sixth dimension, was added to the 5D model (Iddrisu and Bhattacharyya, 2015) and a 6D sustainability approach was presented (Figure 1), comprised social, economic, environmental, institutional, technical and IT dimensions.

\subsection{Technical sustainability}

This dimension demonstrates the ability of the system to meet the present and future needs of the society. It also evaluates the structure of the system, its infrastructure, as well as its inputs and outputs (Iddrisu and Bhattacharyya, 2015).

\subsection{Economic sustainability}

It considers whether investment is economically viable to encourage new investment. In fact, it assesses whether this system is cost-effective for society or not (Iddrisu and Bhattacharyya, 2015).

\subsection{Social sustainability}

This dimension points to the benefits of systems for a society. In fact, it measures social acceptance and community access to the system (Iddrisu and Bhattacharyya, 2015).

\subsection{Environmental sustainability}

It examines the negative impact of the system on the environment. One of the criteria for evaluating systems is the extent of its pollution and its environmental impacts (Iddrisu and Bhattacharyya, 2015). It should be noted that the term "environment" means "green" unless otherwise is indicated. This term should not be confused with the term "business

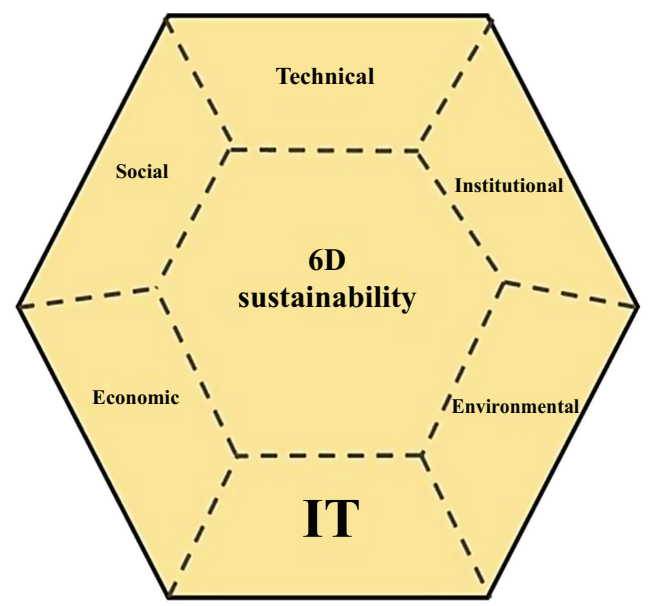

Figure 1. 6D sustainability approach
Supply chain sustainability risk analysis 
MSCRA

2,4

environment" used to describe the organizational environment of a company (Cousins et al., 2004).

\subsection{Institutional sustainability}

This dimension shows the extent of local participation in control and management of systems, as well as local plans and regulations, national development plans and extent of investor and consumer support. Organizational staff participation, motivation, productivity and human resource efficiency are also highlighted in this dimension. It correspondingly evaluates political decisions about the future structure of a system (Iddrisu and Bhattacharyya, 2015).

\subsection{IT sustainability}

It extends to control and management of intra- and inter-organizational and office automation information systems (Funk, 2015), relationship between IT and communication with human development (Gouvea et al., 2018), as well as knowledge management-related issues (Nazim and Mukherjee, 2013) and role of IT infrastructure (Haneefa, 2007).

\section{Research methodology}

According to the related literature review, there are two research streams in supply chain management. The first stream is exploratory research, seeking out conceptual discussions in this area. The second one is associated with mathematical models and techniques, aiming to set decision-making rules in this regard (Agrell et al., 2004). In the research field of this study, telecommunication supply chain decision-makers as a case study demanded initial identification and classification of sustainability risks in this area. They also intended to separate and rank these risks after identification. But then, they made efforts to know how to handle these risks with authentic techniques. It is worth mentioning that, Giannakis and Papadopoulos (2016) stated that risk management approach could be useful in development of a tool for management of sustainability-related risks. As mentioned earlier, this research methodology was selected to implement sustainable supply chain risk management based on the study by Giannakis and Papadopoulos (2016) and then validated by the approval of the experts participating in the study. The research method is illustrated in the following flowchart (Figure 2).

In this study, evaluation was performed using the FMEA method as an analytical technique based on the principle of pre-occurrence prevention to identify potential failure factors in sensitive systems (Mohammadfam and Kianfari, 2008).

\subsection{Data collection}

Prior to the distribution of the questionnaire in this study, respondents were provided with a guide on how to complete the items associated with risk assessment process and how to evaluate the risks. In the next step, the items and the worksheets were prepared using the FMEA method (Dabiri, 2009). Then, a preliminary review of the risks formulated by experts in the form of risk identification teams was carried out and the problems in the meetings were reviewed and resolved. During the brainstorming sessions and interviews with experts, a number of unknown risks with potential effects and risks were also identified and included in the items. The experts included senior executives in technical fields including fixed and mobile data design and development businesses, customers, as well as financial, logistics and human resources, and IT groups engaged in processes of telecommunication networks. 


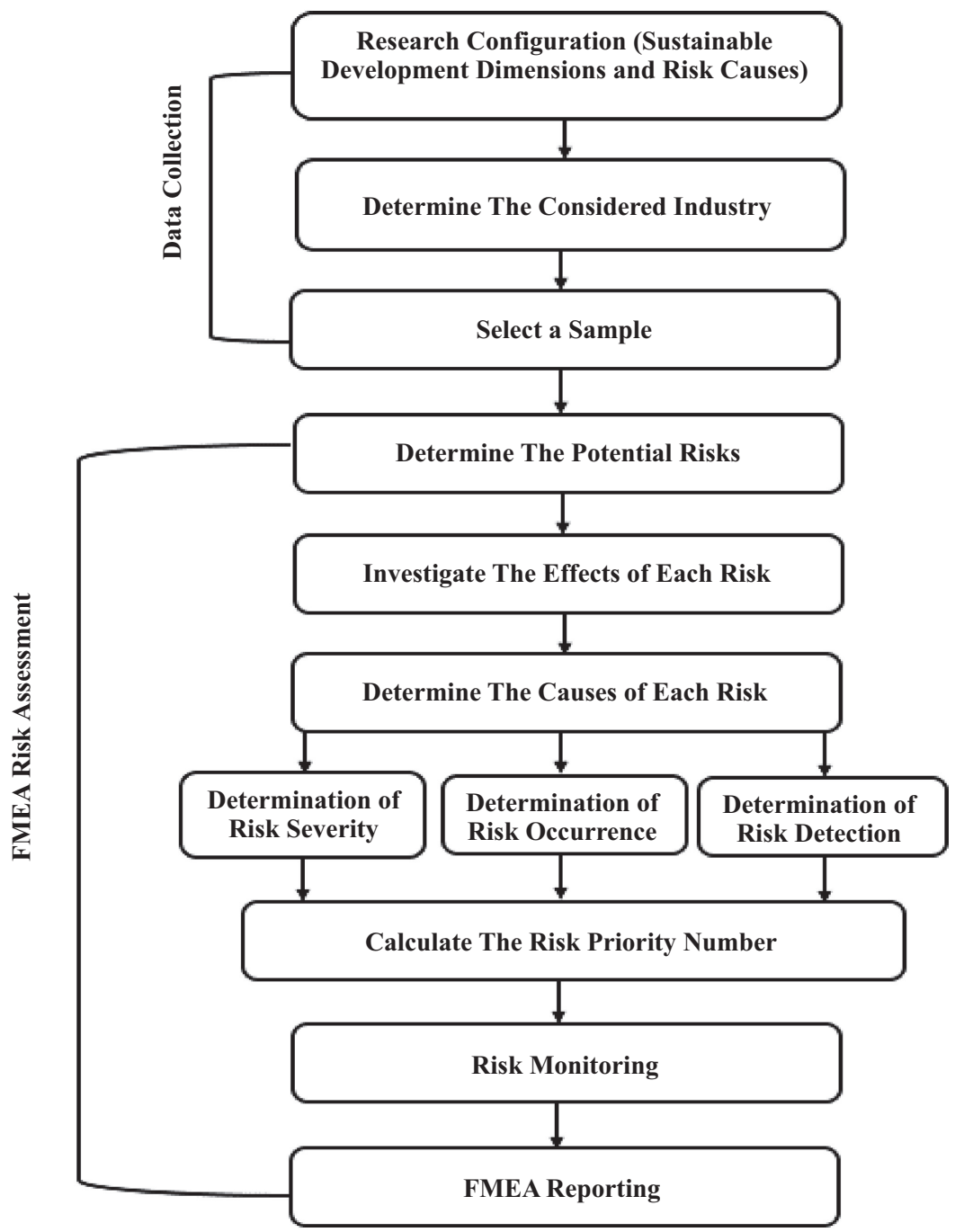

Supply chain sustainability risk analysis

Figure 2.

The flowchart of research method

\subsection{Data processing}

In the risk analysis phase, the causes of the risk and their likely consequences were determined through interviewing with industry experts using the Process Hazard Analysis (PHA)-Pro 6 software. Table 4 shows root causes and potential consequences of each risk in addition to the RPN values of the identified risks. Afterwards, optimal risk management strategy was selected from four strategies. Table A1 presents appropriate strategies to deal with all risks including normal, semi-critical and critical ones using the PHA-Pro 6 software.

6.2.1 Data identification. The final list was determined by experts and managers. Ultimately, 256 strategic risks were identified with long-term effects on sustainability of telecommunications companies (see Table in Table A1). Any supply chain sustainability risks suggested by industry experts to each of the six dimensions of sustainable development 
MSCRA

2,4

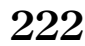

in the four sections of the supply chain were then placed in a single cell in Table 1 . The most efficient supply chain segment and the most effective dimensions of sustainable development could thus contribute to sustainability of supply chain management in Iranian telecommunication companies.

The risks identified in Section 6.2.1 and categorized in Table 1 are entered into the data processing section to address the main questions of the study, i.e. identification, classification, and ranking of risks. Indeed, after identifying all the risks, placing each of the risks in each of the cells in Table 3 led to classification of the supply chain sustainability risks and frequency of risks in each of the table cells showed the vulnerable points of the supply chain. Then, using the RPN relationship, the severity of the impact of each risk was identified and the risks were ranked. According to the experts, the ways to deal with each of the risks was determined. The acronyms used in Table 1 are as follows:

(1) $\mathrm{Su}=$ Suppliers

(2) $\mathrm{Te}=$ Technical

(3) Or = Organization

(4) $\mathrm{Cu}=$ Customers

(5) $\mathrm{En}=$ Environmental

(6) $\mathrm{Ec}=$ Economic

(7) In = Institutional

(8) So $=$ Social

(9) IT = Information Technology

6.2.2 Assessing identified risks (i.e. RPN calculation). The first phase in data processing is risk assessment. One of the most risk identification approaches used in this respect is accordingly the FMEA method (Krzemień et al., 2016).

Each risk assessment method has its own advantages and disadvantages. In this study, the FMEA method was used for the following reasons:

(1) The best features of the FMEA action are post-operative reactive operations instead of failing or taking preoperative precautionary measures, since large amounts of money are often spent in the event of an accident to eliminate its effects (Abdul Hamidzadeh et al., 2014).

(2) The FMEA method is a basic system that identifies and eliminates failures, conflicts and errors existing in works, products, purchases and discoveries.

(3) It includes product maintenance and product purchase (Dadfar et al., 2016).

Table 1.

Risk management matrix- Classification of the identified risks in terms of sustainable dimensions

\begin{tabular}{llllll}
\hline & \multicolumn{2}{c}{ Supply chain sections } & & \multicolumn{2}{c}{ Risks categories } \\
Environmental & Customers & Organization & Suppliers & & Dimensions of \\
\hline En.Te & Cu.Te & Or.Te & Su.Te & Technical & sustainability \\
En.Ec & Cu.Ec & Or.Ec & Su.Ec & Economic & \\
En.In & Cu.In & Or.In & Su.In & Institutional & \\
En.So & Cu.So & Or.So & Su.So & Social & \\
En.IT & Cu.IT & Or.IT & Su.IT & IT & \\
En.En & Cu.En & Or.En & Su.En & Environmental & \\
& & & & &
\end{tabular}


In the FMEA method, risk assessment involves calculation of RPN of each risk. This parameter is calculated with formula (1) below:

$$
\mathrm{RPN}=S \times O \times D
$$

Wherein, $S$ denotes failure severity, $O$ is failure occurrence, and $D$ is likelihood of detection. In this phase, risk effect values ranged from 1 to 10 for failure severity $(\mathrm{S})$, occurrence $(\mathrm{O})$, and detection (D) rates according to Table 2, based on team's scores (68 managers and 78 experts); and then the RPN of each risk was calculated according to formula (1) (Rezaee et al., 2016; Lillie et al., 2015; Chin et al., 2029; Bowles and Peláez, 1995; Xu et al., 2002).

In FMEA, the values of $S, O$, and $D$ vary between 1 and 10 as shown in Table 2.

Since there is no reference RPN value in the FMEA method to determine the data by comparing values and determining risk levels, statistical methods were used in this research. Therefore, firstly, a risk criterion or a risk confidence interval was obtained and subsequently risk levels were determined (Kumar et al., 2009). The average RPN and then the standard deviation (SD) were thus calculated using the following relations.

To obtain the risk levels, risk criterion or risk confidence interval was calculated and risk levels were determined (Kumar et al., 2009).

The IBM SPSS Statistics (version 24) software was used to calculate the mean of RPNs $\left(\mu_{\mathrm{RPN}}\right)$ and the $\mathrm{SD}$ of risk priority $\left(\sigma_{\mathrm{RPN}}\right)$. Confidence intervals and risk levels are shown in Figure 3.

The confidence interval values were obtained from the following relationships:

$$
\operatorname{Min}_{\mathrm{RPN}}=1, \mu_{\mathrm{RPN}}=143.58, \sigma_{\mathrm{RPN}}=69.496
$$$$
\mu_{\mathrm{RPN}}-\sigma_{\mathrm{RPN}}=143.58-69.496=74.08
$$$$
\mu_{\mathrm{RPN}}+\sigma_{\mathrm{RPN}}=143.58+69.496=214.07
$$

$$
\operatorname{Max}_{\mathrm{RPN}}=1000
$$

The risks were also classified as follows:

(1) Level 1: A normal level that does not require any preventive measure, that:

\begin{tabular}{llrlrl}
\hline Rating & Detection (D) & Rating & Occurrence(O) & Rating & Severity(S) \\
\hline 10 & Absolute uncertainty & 10 & (>1in 2) Very High & 10 & Hazardous without warning \\
9 & Very remote & 9 & $($ lin 3) Very High & 9 & Hazardous with warning \\
8 & Remote & 8 & $($ lin 8$)$ High & 8 & Very high \\
7 & Very low & 7 & $($ lin 20) High & 7 & High \\
6 & Low & 6 & $($ lin 80) Moderate & 6 & Moderate \\
5 & Moderate & 5 & $($ lin 400) Moderate & 5 & Low \\
4 & Moderately high & 4 & $($ lin 2000) Moderate & 4 & Very low \\
3 & High & 3 & $($ lin 15,000) Low & 3 & Minor \\
2 & Very high & 2 & $($ lin 150000) Low & 2 & Very minor \\
1 & Almost certain & 1 & $($ lin 1500000) Remote & 1 & None \\
\hline
\end{tabular}

Supply chain sustainability risk analysis

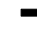
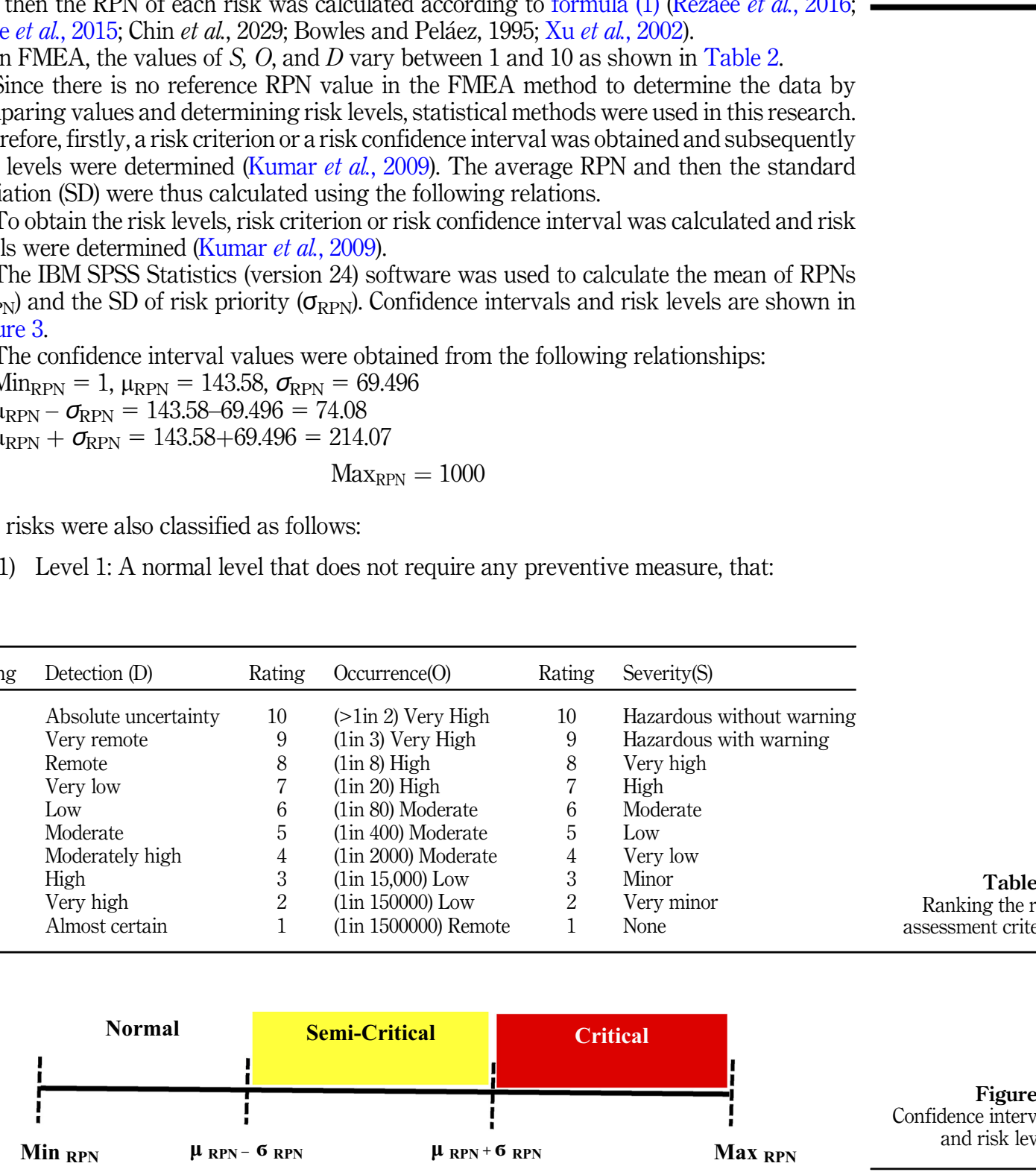

Figure 3. Confidence intervals and risk levels

Table 2. Ranking the risk assessment criteria 
MSCRA

2,4

224

$\mathrm{RPN}<\left(\mu_{\mathrm{RPN}}-\sigma_{\mathrm{RPN}}\right)=74.08$

(2) Level 2: A semi-critical level that needs preventive measure,

$\left(\mu_{\mathrm{RPN}}-\sigma_{\mathrm{RPN}}\right)=74.08 \leq R P N \leq\left(\mu_{\mathrm{RPN}}+\sigma_{\mathrm{RPN}}\right)=214.07$

(3) Level 3: A critical level that demands urgent preventive measures, that:

$\left(\mu_{\mathrm{RPN}}+\sigma_{\mathrm{RPN}}\right)=214.07<\mathrm{RPN}$

Columns 3-6 of Table (see Table A1) display the mean RPN values of 59 critical risks in a descending order. It should be mentioned that, only the critical risks are listed in the Tables with respect to the large number of identified risks.

6.2.3 Risk analysis. In the risk analysis phase, the causes of the risks and their likely consequences were determined via interviewing with industry experts using the PHA-Pro 6 software. In Table (see Table A1), the root causes and potential consequences of each critical risk are shown in addition to the RPN values of the identified risks.

6.2.4 Risk treatment (i.e. strategy adoption). In this section, given the root causes and potential consequences of each risk, one of the accept, avoid, transfer and reduce strategies were adopted. In the case of risks with removable root causes, avoidance of the causes as well as the relationship between the origin of the risk and the risk was terminated and then the risk was eliminated. Regarding some risks, it was possible to reduce the likelihood of occurrence of the risk or its consequences. The transfer strategy was also based on insurance and transfer of risk severity to other parts. With respect to almost inevitable risks, the accept strategy was applied. After adopting the risk treatment strategy, the performance suiting each strategy was identified with the aid of the experts.

In all the Tables in the Appendix, the 9th column presents the treatment strategy adopted for each risk along with the related performance risks.

\section{Numerical results}

According to Table 3 and Figure 4, more than $56 \%$ of telecommunication network supply chain sustainability risks are semi-critical ones that require preventive measures. As can be seen, the number of the critical risks was almost $3 \%$ which was higher than normal. In the case of critical risks, precautions were also needed.

According to Figure 5, economic risks (33.90\%), technical and social critical risks (equally) with an $18.64 \%$ share of supply chain sustainability (respectively) compared with institutional critical risks $(16.95 \%)$, IT critical risks $(10.17 \%)$, and environmental critical risks $(1.69 \%)$ were threatening supply chain sustainability.

Based on Figure 6, economic, technical and institutional semi-critical risks with 30.34\%, $27.59 \%$ and $18.62 \%$ shares of supply chain sustainability, respectively, and social $(15.17 \%)$, IT $(6.90 \%)$, and environmental $(1.38 \%)$ semi-critical risks were considered as threats to supply chain sustainability.

As illustrated in Figure 7, IT and economic normal risks with shares of $30.77 \%$ and $25 \%$ of supply chain sustainability were more significant than structural, technical and environmental normal risks with $17.31 \%, 13.46 \%$ and $3.85 \%$ values, respectively; so, they were threatening supply chain sustainability.

As observed in Figure 8, the main source of supply chain critical risks includes customers, constituting $45.76 \%$ of such risks. Next there is organization, which has a $38.88 \%$ share of critical risk generation. Suppliers and the environment also constitute $13.58 \%$ and $1.69 \%$ of critical risks, respectively. Therefore, it can be concluded that $61.03 \%$ of such risks had been imposed by external factors on the supply chain.

Table 4 shows the distribution of critical risks in terms of supply chain sectors as well as sustainable development dimensions. 


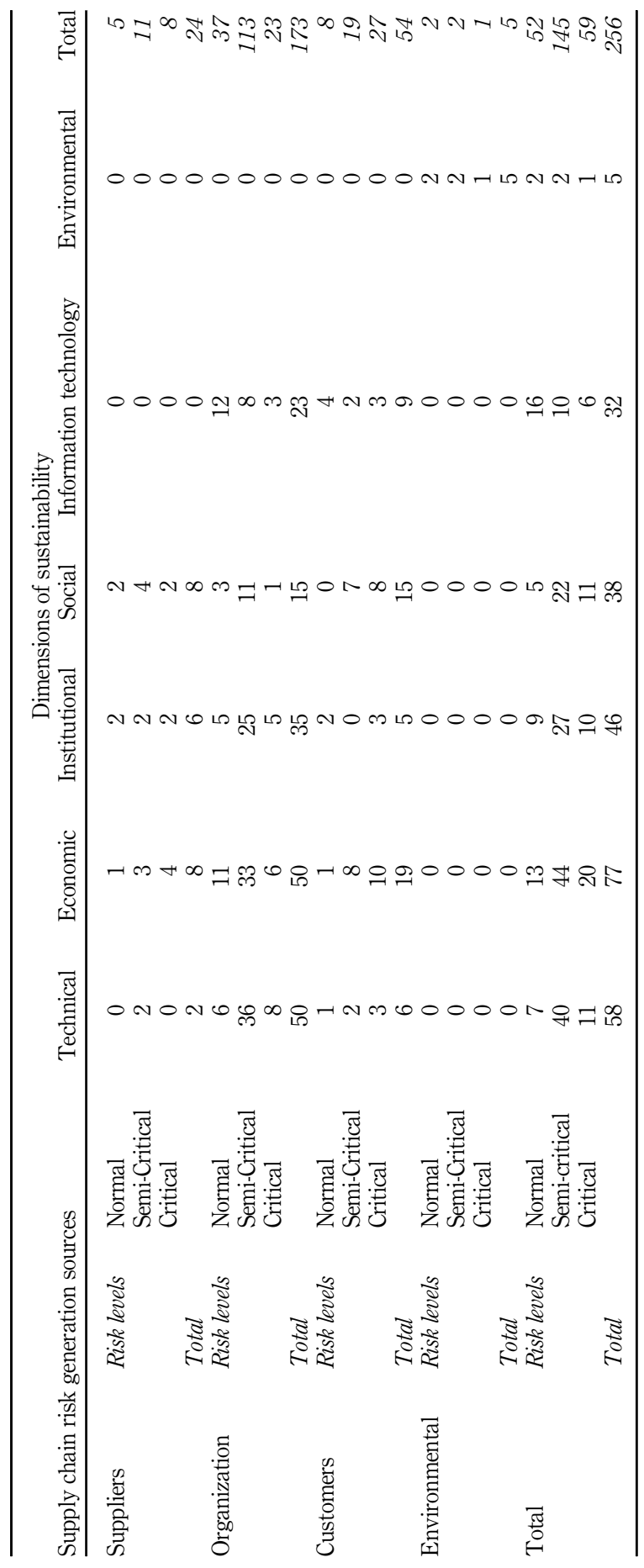

Supply chain sustainability risk analysis

225

Table 3.

The status of the risks generated from the four sources of supply chain risk 
MSCRA

2,4

\section{6}

Figure 4

Distribution of supply

chain

sustainability risks

Figure 5.

Dimensions of sustainability of critical supply chain risks
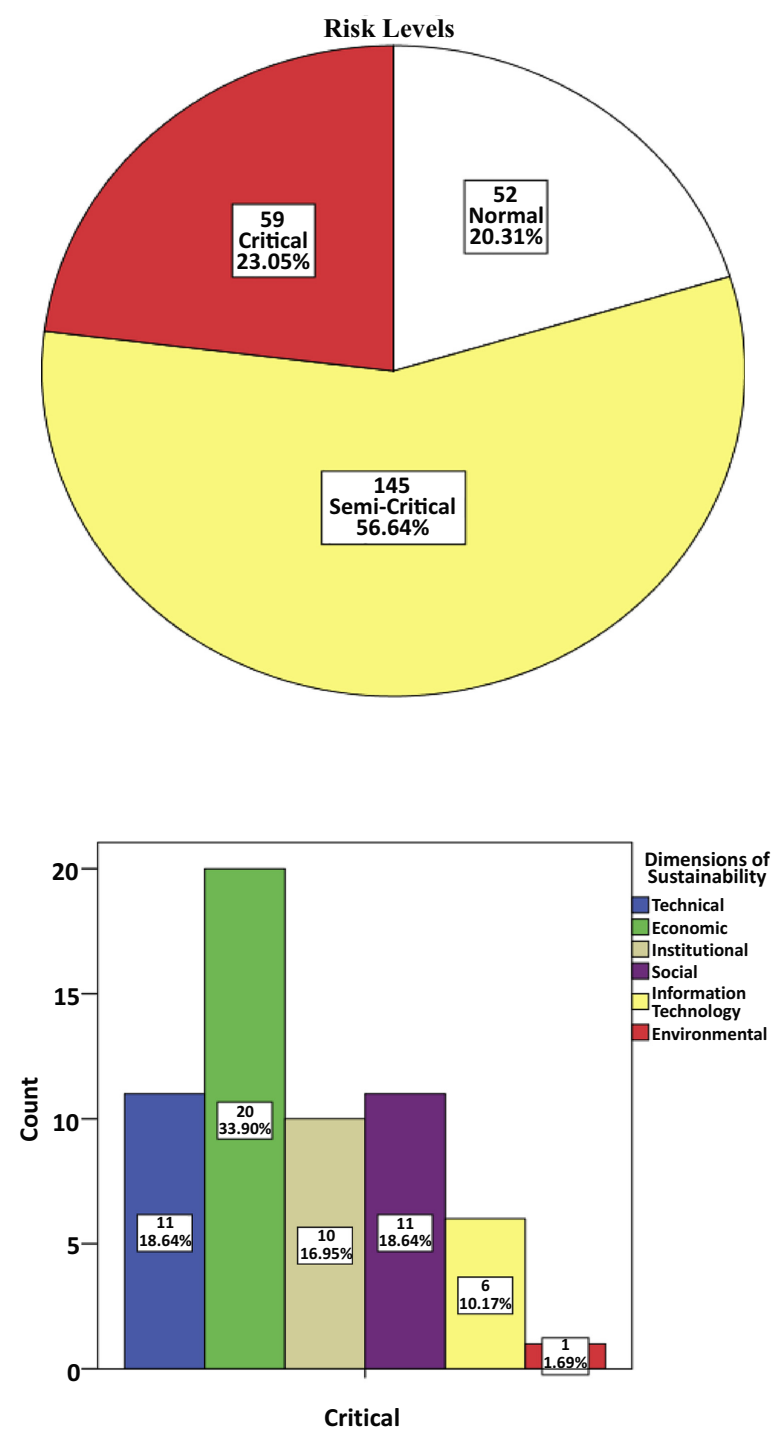

As observed in Figure 9, risks posing significant threats to supply chain sustainability are economic ones affecting customers and organization, institutional risks for organization, economic risks to suppliers and environmental risks threatening the environment with a share of $1.69 \%$; respectively.

As displayed in Figure 10, the main source of supply chain semi-critical risks is organization that accounts for $77.93 \%$ of such risks. After all, it is customer risks, which has a $13.1 \%$ share of semi-critical risks. Suppliers and the environment also constitute $7.59 \%$ and $1.38 \%$ of semi-critical risks, respectively. Therefore, it can be concluded that there is a significant portion of the semi-critical risks associated with supply chain within the 


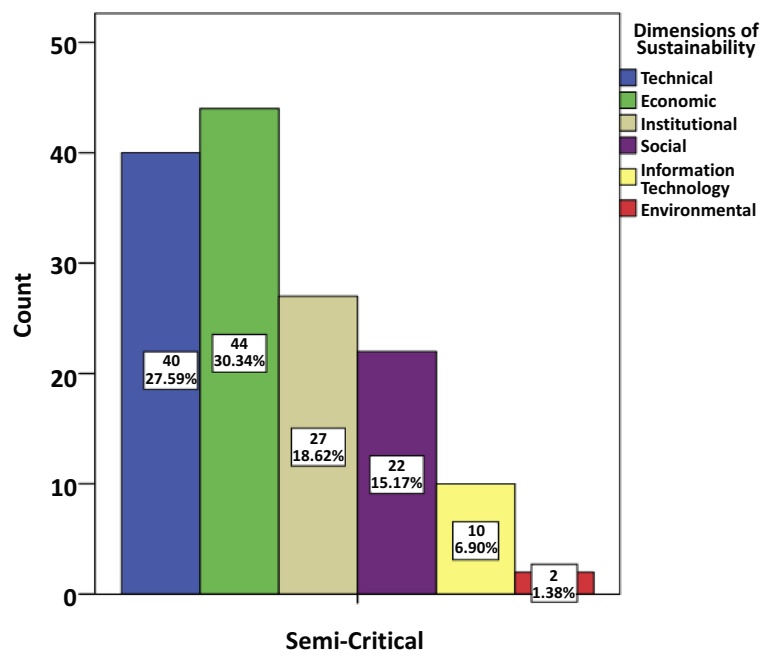

Supply chain sustainability risk analysis

Figure 6.

Dimensions of sustainability of semicritical supply chain risks

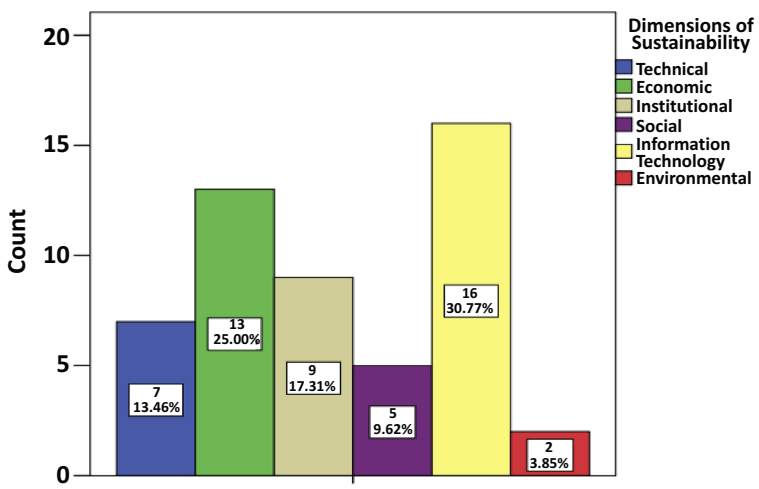

Normal

Figure 7. Dimensions of sustainability of normal supply

chain risks

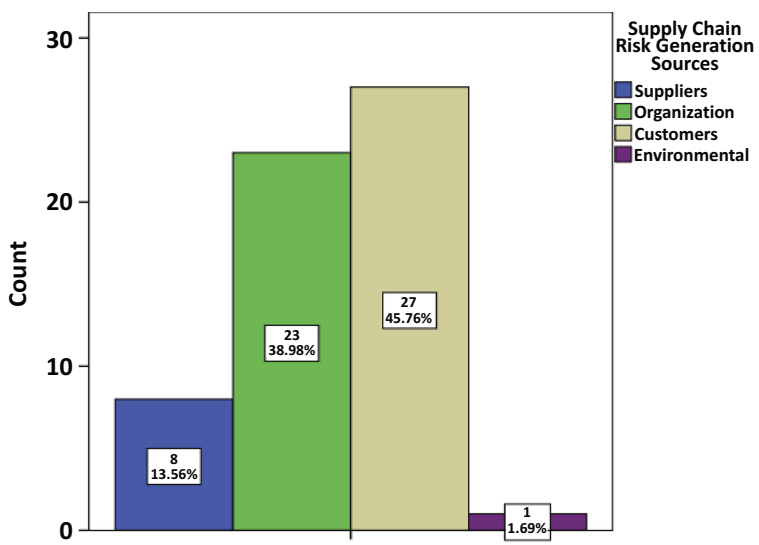

Critical

Figure 8.

Contribution of each supply chain resource to the generation of critical risks 
MSCRA

2,4

\section{8}

Figure 9.

Distribution of critical risks by supply chain production resources and sustainable development dimensions



organization. Also, $22.07 \%$ of semi-critical risks are imposed by external factors on supply chain. These results highlight the importance of enhancing the organization's engagement with suppliers, customers, and the environment as important factors in reducing supply chain semi-critical risks.

Table 5 shows distribution of semi-critical risks by sources of supply chain risk generation and the dimensions of sustainable development.

As can be seen in Figure 11, the most important semi-critical risks for supply chain sustainability, that is technical and economic risks are listed by the organization. From a managerial perspective, the organization of technical and economic risks has been identified as one of the major sources of risks and more attention and funding should be thus devoted to improving the quality and quantity of equipment, human resources expertise and internal organizational social factors. 


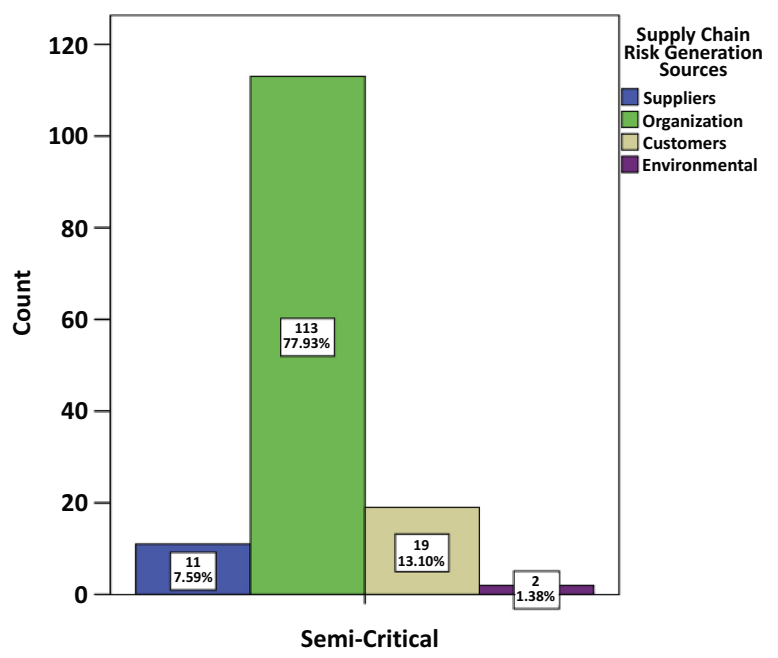

Supply chain sustainability risk analysis

229

Figure 10.

The contribution of each supply chain resource generation source to the production of semicritical risks

To provide a more detailed analysis and understanding of risk generation shares of different supply chain levels and dimensions of sustainable development, there were attempts to identify the riskiest areas and dimensions threatening supply chain sustainability. To this end, critical, semi-critical and normal risks were assigned with 5,3 and 1 weights; respectively. Afterwards, the weighted means of the risks of different supply chain areas and dimensions of sustainable development were calculated (Table 6). Also, in Table (see Table A1), the 10th column introduces these risks.

Then, the risk scores of different supply chain areas and sustainable development dimensions according to Table 7 and analytic hierarchy process (AHP) technique (Habibi, 2014) were calculated using the following formula:

The final weight of each option

$$
=\sum_{\text {For every criterion }} \text { (Option weight compared with that criterion } \times \text { weight of that criterion) }
$$

The final weight of the risk was also calculated by multiplying the risks of each house (number of normal risks multiplied by 1, number of semi-critical risks multiplied by 3 and number of critical multiplied by 5) (Table 7).

As an example, the final weight of Su.Te risk was calculated as follows:

$$
\begin{aligned}
\sum(\text { Risks in Su.Te Houses } \times \text { Risks Weight })= & (\text { Su.Te Critical Risks } \times 5)+(\text { Su.Te Semi } \\
& - \text { Critical Risks } \times 3) \\
& +(\text { Su.Te Normal Risks } \times 1)(0 \times 5)+(2 \times 3) \\
& +(0 \times 1) \\
= & 6
\end{aligned}
$$

Figure 12 shows risk generation shares of each dimension of the sustainable development and each supply chain area. 
MSCRA

2,4

\section{0}

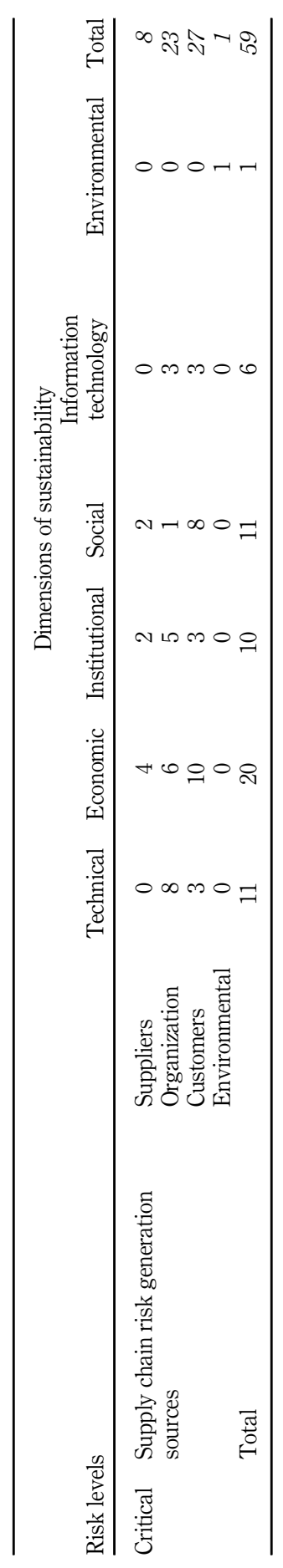

Table 4.

Distribution of critical risks by supply chain production resources and sustainable development dimensions 
Table 5

Distribution of semicritical risks by supply chain risk generation resources and sustainable development dimensions 


\section{MSCRA \\ 2,4}

\section{2}

Figure 11.

Distribution of semicritical risks by different supply chain resources and sustainable development dimensions

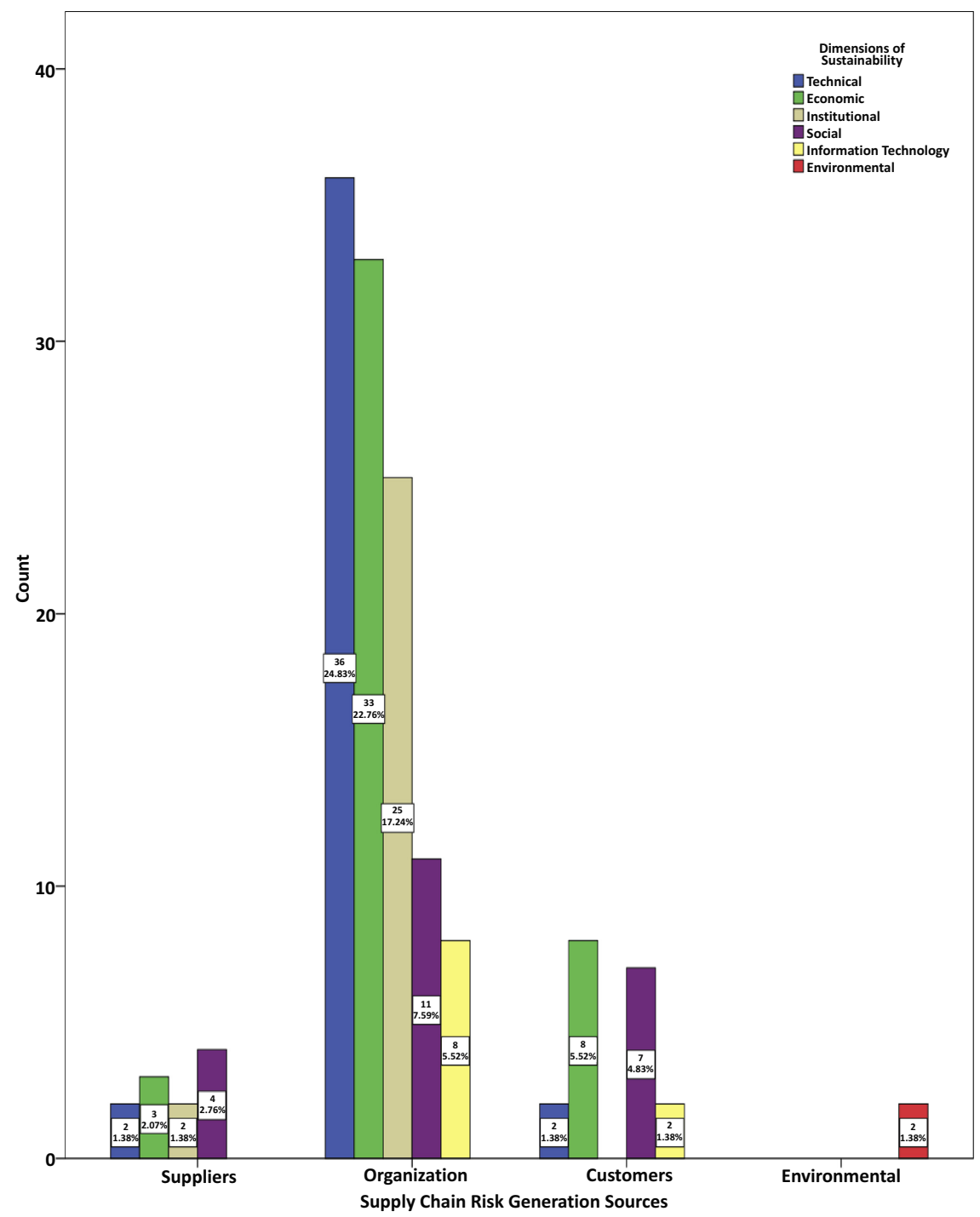

In addition, Figures 13 and 14 depict risk-generation shares of each dimension of sustainable development and each level of the supply chain.

\section{Discussion}

The results of this study supported the findings reported by Valinejad and Rahmani (2018) concerning a new general framework for supply chain sustainability risk management and its use for supply chains in Iran and also provided a scientific approach to managing those risks by studying four parts of the telecommunication supply chain. The sources of risk generation (i.e. suppliers, organizations, customers and the environment) were further 


\begin{tabular}{|c|c|c|c|c|c|c|c|c|}
\hline \multirow{3}{*}{$\frac{\text { Total }}{7}$} & \multicolumn{4}{|c|}{$\begin{array}{l}\text { Supply chain risk generation } \\
\text { resource }\end{array}$} & \multirow{2}{*}{\multicolumn{3}{|c|}{ Risk levels }} & \multirow{2}{*}{$\begin{array}{l}\text { Supply chain } \\
\text { sustainability } \\
\text { risk analysis }\end{array}$} \\
\hline & En & $\mathrm{Cu}$ & Or & $\mathrm{Su}$ & & & & \\
\hline & 0 & 1 & 6 & 0 & $\mathrm{Te}$ & \multirow{7}{*}{ Sustainability dimensions } & \multirow{7}{*}{ Normal } & \\
\hline 13 & 0 & 1 & 11 & 1 & $\mathrm{Ec}$ & & & \\
\hline 9 & 0 & 2 & 5 & 2 & In & & & \\
\hline 5 & 0 & 0 & 3 & 2 & So & & & 233 \\
\hline 16 & 0 & 4 & 12 & 0 & IT & & & \\
\hline 2 & 2 & 0 & 0 & 0 & En & & & \\
\hline 52 & 2 & 8 & 37 & 5 & Total & & & \\
\hline 40 & 0 & 2 & 36 & 2 & $\mathrm{Te}$ & \multirow{6}{*}{ Sustainability dimensions } & \multirow[t]{6}{*}{ Semi-critical } & \\
\hline 44 & 0 & 8 & 33 & 3 & $\mathrm{Ec}$ & & & \\
\hline 27 & 0 & 0 & 25 & 2 & In & & & \\
\hline 22 & 0 & 7 & 11 & 4 & So & & & \\
\hline 10 & 0 & 2 & 8 & 0 & IT & & & \\
\hline 2 & 2 & 0 & 0 & 0 & En & & & \\
\hline 145 & 2 & 19 & 113 & 11 & Total & \multirow{8}{*}{ Sustainability dimensions } & \multirow{8}{*}{ Critical } & $\begin{array}{r}\text { Table } 6 . \\
\text { Situation matrix of }\end{array}$ \\
\hline 11 & 0 & 3 & 8 & 0 & $\mathrm{Te}$ & & & $\begin{array}{l}\text { situation ma-rix or } \\
\text { critical, semi-critical }\end{array}$ \\
\hline 20 & 0 & 10 & 6 & 4 & $\mathrm{Ec}$ & & & and normal risks of \\
\hline 10 & 0 & 3 & 5 & 2 & In & & & each supply chain risk \\
\hline 11 & 0 & 8 & 1 & 2 & So & & & generation resource \\
\hline 6 & 0 & 3 & 3 & 0 & IT & & & related to \\
\hline 1 & 1 & 0 & 0 & 0 & En & & & sustainability \\
\hline 59 & 1 & 27 & 23 & 0 & Total & & & dimensions \\
\hline
\end{tabular}



identified and the impact of their risks on supply chain sustainability was consequently classified into five environmental, social, economic, technical and institutional dimensions. This study also added the sixth dimension of IT sustainability to the 5D model (Iddrisu and Batacharya, 2015) presented in the related literature (Valinejad and Rahmani, 2018).

Identifying critical risks based on the results of this study revealed that the main source of critical supply chain risks was customers, constituting $45.76 \%$ of these risks. The next sources were organizational risks, accounting for $38.98 \%$ of critical risk generation, as well as suppliers and the environment having $13.56 \%$ and $1.69 \%$ shares of such risks; respectively. The results of this study could not be compared with the findings reported by Valinejad and Rahmani (2018) who identified the highest critical risks in suppliers with $53 \%$ of total critical risks followed by the environment with $27 \%$ and organization and customers having $13 \%$ and $7 \%$ shares, respectively, of total critical risks in the supply chain.

In terms of identifying semi-critical risks and according to the results of this study, organization was the main source of semi-critical risks arising from supply chain, which 
MSCRA

2,4

\section{4}

180
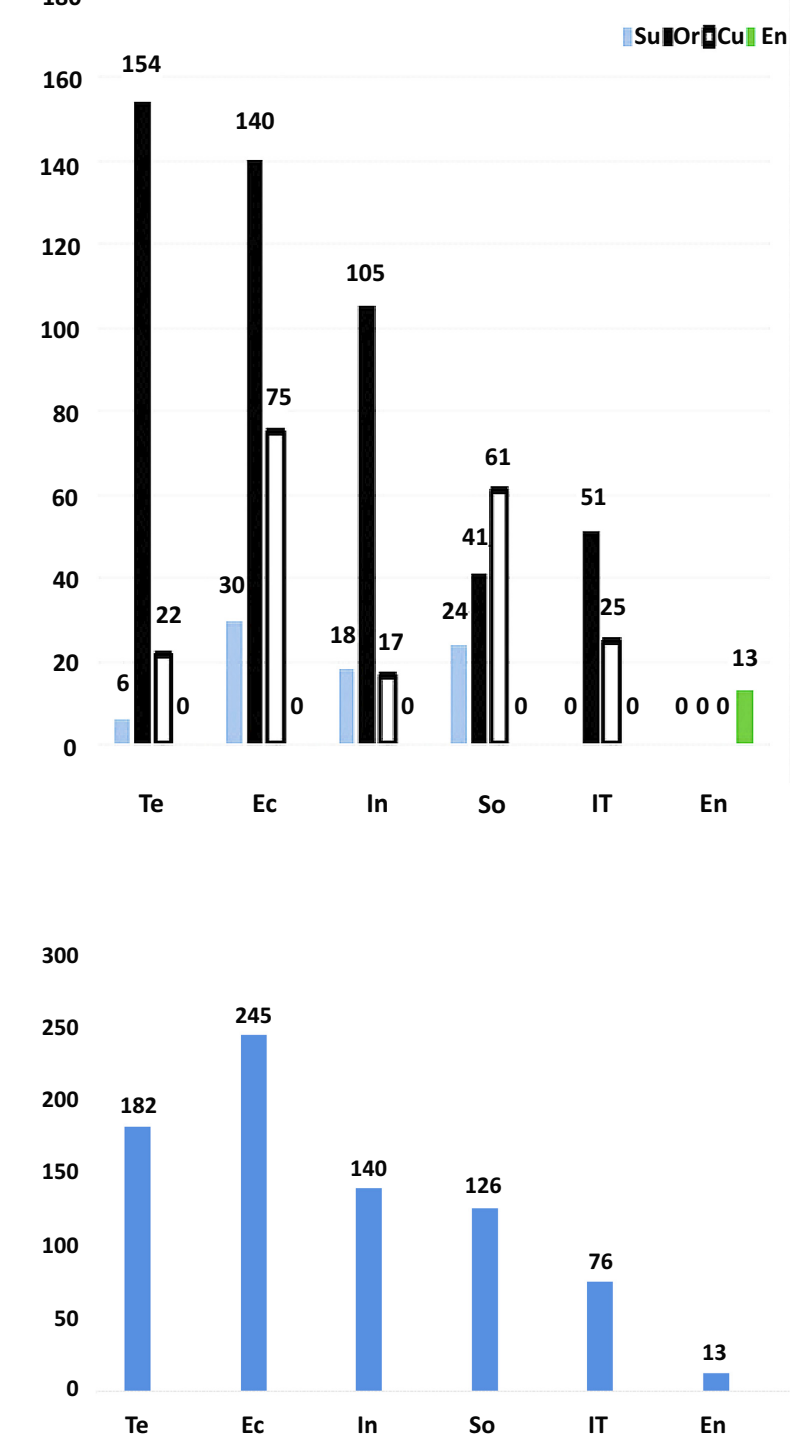

Te $\quad$ Ec
En
Figure 12.

The score of each part of the supply chain and each sustainable

development

dimension in relation to its risk

generation share
Figure 13.

The risk generation

scores of each

dimension of

sustainability

made up $77.93 \%$ of these risks, and then customers constituting $13.1 \%$ share of semi-critical risk sources. The environment and suppliers had lower shares of semi-critical level risks, with $1.38 \%$ and $7.59 \%$ shares, respectively, consistent with the findings by Valinejad and Rahmani (2018); showing that organization was the main source of mid-level risks due to supply chain $(58 \%)$. The results were also in line with the highest share for organization $(77.93 \%)$ but not for other semi-critical risks wherein the environment accounted for $20 \%$ of the semi-critical share and suppliers and customers had a lower share of the semi-critical risk $(11 \%)$. 


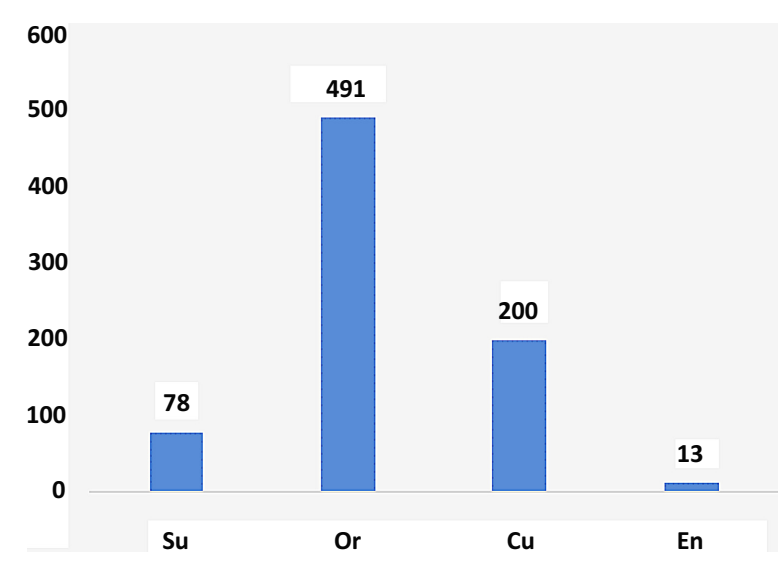

\section{Management decisions}

The results could provide a good roadmap for supply chain managers especially in telecommunication industry in terms of dealing with supply chain sustainability risks. In addition, grouping fulfilled in the risk management matrix could enable managers to identify talent segments in supply chain sustainability risks and to adopt appropriate strategies towards each risk.

Moreover, critical, semi-critical, and normal levels were defined for risk ratings through statistical methods. Given the large number of supply chain sustainability risks, this classification could help managers identify the most dangerous risks and to allocate resources needed to deal with them. However, while the critical risks were the most dangerous ones, half-risks and even ordinary ones could collectively threaten environmental sustainability in the long run. All of these could have irreparable impacts on long-term sustainable development which should be considered in the long-term planning of organizations. Managers should therefore focus on enhancing professional capacity by motivating staff to increase productivity, supplying and improving equipment, boosting quality and quantity of technical equipment, increasing engagement with media partners and enhancing interoperability of information systems.

\section{Conclusion}

In this study, previously presented models were developed to evaluate the risks of Iranian telecommunication networks in supply chain sustainability by adding the sixth dimension of IT.

Economic risks with $33.90 \%$, technical and social critical risks (equally) with $18.64 \%$ share of supply chain sustainability (respectively) compared with institutional (16.95\%), IT $(10.17 \%)$ and environmental $(1.69 \%)$ critical risks were threatening supply chain sustainability.

The main source of supply chain critical risks included customers, constituting $45.76 \%$ of such risks. Next to this was organization as a risk source, which had a $38.88 \%$ share of critical risk generation. Suppliers and the environment also represented $13.58 \%$ and $1.69 \%$ of critical risks, respectively. Therefore, it could be concluded that $61.03 \%$ of the critical risks had been imposed by external factors on the supply chain. For example, during the interview, experts reported problems related to equipment shortages and quality, lack of financial resources, as well as theft of cables that had led to supply chain instability, along with inadequate training, 
MSCRA

2,4

236 and lack of knowledge management at the level of telecommunication networks that had been also reported to result in supply chain instability.

Economic, technical, and institutional semi-critical risks with values of $30.34 \%, 27.59 \%$ and $18.62 \%$, respectively, and social $(15.17 \%)$ and IT $(6.90 \%)$ semi-critical risks as well as environmental semi-critical risks $(1.38 \%)$ were considered as threats to supply chain sustainability.

The main source of supply chain semi-critical risks was organization, accounting for $77.93 \%$ of the semi-critical risks. After all, it was customer risks, which had a $13.1 \%$ share in generating semi-critical risks. Suppliers and the environment also constituted $7.59 \%$ and $1.38 \%$ of the semi-critical risks, respectively. Therefore, it could be concluded that there was a significant portion of the semi-critical risks associated with supply chain within the organization. Also, $22.07 \%$ of the semi-critical risks had been imposed by external factors on the supply chain. These results highlighted the importance of enhancing the organization's engagement with suppliers, customers and the environment as important factors reducing supply chain semi-critical risks.

IT and economic normal risks with the shares of $30.77 \%$ and $25 \%$ of supply chain sustainability were also more significant than structural, technical and environmental normal risks with $17.31 \%, 13.46 \%$ and $3.85 \%$ shares, respectively, in supply chain sustainability, that were threatening.

\section{Future research}

In the near future, telecommunication networks will be obliged to exploit emerging technologies such as the internet of Things (IoT) and blockchain in the field of IT to meet the growing needs of customers and to adapt to international customers. Accordingly, it is recommended that future research focus on telecommunication supply chain sustainability, assessing critical IoT and blockchain risks associated with supply chain sustainability of telecommunication networks.

In this study, one of the important reasons for the shortage of financial resources and technical equipment was also introduced. Therefore, risk management was one of the sustainability management tools. It was thus suggested to investigate other methods of supply chain sustainability to evaluate the control of financial and technical resources and to present the results of both studies. The most successful technique is the one optimizing savings and increasing productivity in supply chain resources, especially financial and technical ones.

In this study, IT was identified as the sixth dimension that could threaten supply chain sustainability. Also, critical, semi-critical and normal risks associated with this dimension were identified. Since customer learning and knowledge they need to use telecommunication services has an undeniable role in supply chain sustainability, it is suggested to reflect on the role of knowledge and IT management in controlling important customer risks to supply chain sustainability in future studies.

\section{References}

Abdolhamidzadeh, B. and Badri, N. (2014), Quantitative and Qualitative Assessment of Risk in Process Industries and Description of Industrial Hazard Identification Methods Focusing on the HAZOP Method, Andisheh Sara Publishing, Tehran.

Agrell, P.J., Lindroth, R. and Norrman, A. (2004), "Risk, information and incentives in telecom supply chains", International Journal of Production Economics, Vol. 90 No. 1, pp. 1-16.

Ahmadi, H.B., Petrudi, S.H.H. and Wang, X. (2008), "Integrating sustainability into supplier selection with analytical hierarchy process and improved grey relational analysis: a case of telecom 
industry", The International Journal of Advanced Manufacturing Technology, Vol. 90 No. 1, pp. 2413-2427.

Arabian-Hoseynabadi, H., Oraee, H. and Tavner, P.J. (2010), "Failure modes and effects analysis (FMEA) for wind turbines", International Journal of Electrical Power and Energy Systems, Vol. 32 No. 7, pp. 817-824.

Arabi, M., Mansour, S. and Shokouhyar, S. (2017), "Optimizing a warranty-based sustainable product service system using game theory", International Journal of Sustainable Engineering, Vol. 11 No. 5, pp. 330-341.

Bagheri, P. and Hassan, K.H. (2012), "Electronic commerce and consumer Protection development in Iran: policy and infrastructural influences", International Business Management, Vol. 6 No. 3, pp. 333-339.

Bifulco, F., Tregua, M., Amitrano, C.C. and D'Auria, A. (2016), "ICT and sustainability in smart cities management", International Journal of Public Sector Management, Vol. 29 No. 2, pp. 132-147.

Cousins, P.D., Lamming, R.C. and Bowen, F. (2004), "The role of risk in environment-related supplier initiatives", International Journal of Operations \& Production Management, Vol. 24 No. 6, pp. 554-565.

Dabiri, G. (2009), FMEA Analysis of Potential Damage Situations and Their Implications and Implementation Methods, Iran Industrial Research and Training Center, Tehran.

Dadfar, S., Abrisham, S. and Khanpour, M. (2016), FMEA Risk Assessment, Royan Pajouh Publishing, Tehran.

Eneh, O.C. (2015), "Environmental pollution health effects of electromagnetic radiations from antennae of telecommunication masts erected near residential and educational facilities in Enugu", Ciência e Técnica Vitivinícola Journal, Vol. 30 No. 9, pp. 146-154.

Feili, H.R., Akar, N., Lotfizadeh, H., Bairampour, M. and Nasiri, S. (2013), "Risk analysis of geothermal power plants using Failure Modes and Effects Analysis (FMEA) technique", The International Journal of Management, pp. 69-76.

Funk, J.L. (2015), "IT and sustainability: new strategies for reducing carbon emissions and resource usage in transportation”, Telecommunications Policy, Telecommunications Policy, Vol. 39 No. 1, pp. 861-874.

Garcia, P.A.A., Schirru, R., Frutuoso, P.F. and Melo, E. (2005), “A fuzzy data envelopment analysis approach for FMEA", The International Journal of Progress in Nuclear Energy, Vol. 46 Nos 3-4, pp. 359-373.

Giannakis, M. and Papadopoulos, T. (2016), "Supply chain sustainability: a risk management approach”, International Journal of Production Economics, Vol. 171, pp. 455-470.

Giffinger, R., Kramar, H. and Kalasek, R. (2007), "Smart cities ranking of European medium-sized cities", Centre of Regional Science, Vienna University of Technology.

Gouvea, R., Kapelianis, D. and Kassicieh, S. (2018), "Assessing the nexus of sustainability and information and communications technology", Technological Forecasting and Social Change, Vol. 130, pp. 39-44.

Gurnani, H., Ray, S. and Wang, Y. (2011), "Special issue of production and operations management: "global supply chain risk management", Production and Operations Management, Vol. 20 No. 3, pp. 489-489.

Hallikas, J., Virolainen, V.M. and Tuominen, M. (2002), "Risk analysis and assessment in network environments: a dyadic case study", International Journal of Production Economics, Vol. 78 No. 1, pp. 45-55.

Haneefa, M. (2007), "Application of information and communication technologies in special libraries in Kerala (India)", Library Review, Vol. 56 No. 7, pp. 603-620.

Iddrisu, I. and Bhattacharyya, S.C. (2015), "Sustainable Energy Development Index: a multidimensional indicator for measuring sustainable energy development", Renewable and Sustainable Energy Reviews, Vol. 50, pp. 513-530.

Supply chain sustainability risk analysis 
MSCRA

2,4

Krzemień, A., Sánchez, A.S., Fernández, P.R., Zimmermann, K. and Coto, F.G. (2016), “Towards sustainability in underground coal mine closure contexts: a methodology proposal for environmental risk management”, Journal of Cleaner Production, Vol. 139, pp. 1044-1056.

Kumar, V., Mari, M., Schuhmacher, M. and Domingo, J.L. (2009), "Partitioning total variance in risk assessment: application to a municipal solid waste incinerator", Environmental Modelling and Software, Vol. 24 No. 2, pp. 247-261.

Li, Y., Li, Y. and Li, J. (2015), "An application and management system of smart city", in Yang, L. and Zhao, M. (Eds), Proceedings International Industrial Informatics and Computer Engineering Conference, Atlantis Press, Amsterdam, Vol. 12, pp. 1626-1630.

Mir Fakhreddini, S.H., PourHamidi, M. and Mir Fakhreddini, F.S. (2012), "Ranking potential harmful situations using fuzzy cluster analysis case study: steel alloy steel company of Iran", Journal of Industrial Management Studies Tenth Year, Vol. 27, pp. 68-93.

Nazim, M. and Mukherjee, B. (2013), "Knowledge management competencies required among library and information science professionals: an Indian perspective", Library Review, Vol. 62 Nos 6/7, pp. 375-387.

Mandal, S. and Maiti, J. (2014), "Risk analysis using FMEA: fuzzy similarity value and possibility theory based approach", Expert Systems with Applications, Vol. 41 No. 7, pp. 3527-3537.

Mohammadfam, A. and Kianfar, A. (2008), "Application of hazard study operation technique (HAZOP) in safety, health and environmental hazards assessment", Journal of Environmental Science and Technology, Vol. 1, pp. 39-40.

Narasimhan, R. and Talluri, S. (2009), "Perspectives on risk management in supply chains", Journal of Operations Management, Vol. 27 No. 2, pp. 114-118.

Nazari, A., Forsatkar, E. and Kiafar, B. (2008), Risk Management in Projects, Vice President of Strategic Planning and Supervision, Tehran.

NingcongXiao, H.Z., YanfengLi, L. and Tongdan, J. (2011), "Multiple failure modes analysis and weighted risk priority number evaluation in FMEA", The International Journal of Engineering Failure Analysis, Vol. 18 No. 4, pp. 1162-1170.

Pickard, K., Müller, P. and Bertsche, B. (2005), Multiple Failure Mode and Effects Analysis: An Approach to Risk Assessment of Multiple Failures with FMEA, Reliability and maintainability symposium, 2005 Annual, Institute of Electrical and Electronics Engineers, Piscataway, pp. 457-62.

Rezaee, M.J., Salimi, A. and Yousefi, S. (2016), "Identifying and managing failures in stone processing industry using cost-based FMEA", The International Journal of Advanced Manufacturing Technology, pp. 1-14.

Rezaei, S., Shokouhyar, S. and Zandieh, M. (2019), "A neural network approach for retailer risk assessment in the aftermarket industry", Benchmarking: An International Journal, Vol. 26 No. 5 , pp. 1631-1647.

Schmittner, C., Gruber, T., Puschner, P. and Schoitsch, E. (2014), "Security application of failure mode and effect analysis (FMEA)", Computer Safety, Reliability, and Security, SAFECOMP 2014, in Lecture Notes in Computer Science, Springer, Cham, Vol. 8666, pp. 310-325.

Segismundo, A. and Cauchick Miguel, P.A. (2008), "Failure mode and effects analysis (FMEA) in the context of risk management in new product development: a case study in an automotive company", International Journal of Quality and Reliability Management, Vol. 25, No. 9, pp. 899-912.

Seuring, S. and Muller, M. (2008), "Core issues in sustainable supply chain management - a Delphi study", Business Strategy and the Environment, Vol. 17 No. 8, pp. 455-466.

Shokohyar, S., Mansour, S. and Karimi, B. (2013), "Simulation-based optimization of ecological leasing: a step toward extended producer responsibility (EPR)", The International Journal of Advanced Manufacturing Technology, Vol. 66 Nos 1/4, pp. 159-169.

Shokohyar, S., Taati, E. and Zolfaghari, S. (2017), "The effect of drivers' demographic characteristics on road accidents in different seasons using data mining", PROMET - Traffic and Transportation, Vol. 29 No. 6, pp. 555-556. 
Shokouhyar, S., Noorbakhsh, A. and Aalirezaei, A. (2017), "Evaluation of Green IT services with fuzzy screening approach", Australasian Journal of Information Systems, Vol. 27 No. 1, pp. 1-21.

Shokouhyar, S., Safari, S. and Mohsenian, F. (2018), "Improving candy industry competitiveness: retailers' perception regarding customer satisfaction”, Journal of Food Products Marketing, Vol. 24 No. 6, pp. 761-783.

Shokouhyar, S., Pahlevani, N. and Mir Mohammad Sadeghi, F. (2019), "Scenario analysis of smart, sustainable supply chain on the basis of a fuzzy cognitive map", Management Research Review, Vol. 43 No. 4, pp. 463-496, doi: 10.1108/MRR-01-2019-0002.

Singh, R.K., Luthra, S., Mangla, S.K. and Uniyal, S. (2019), "Applications of information and communication technology for sustainable growth of SMEs in India food industry", Resources, Conservation and Recycling, Vol. 147, pp. 10-18.

United Nations International Trade Agreement on Liability (2010), "Supply chain sustainability: a practical guide for continuous improvement", United Nations Global compact and BSR,2010, United Nations(UN), UNDESA, 2014, International Decade for Action Water for Life, available at: http://www.un.org/water for life decade/scarcity.shtml.

Valinejad, F. and Rahmani, D. (2018), "Sustainability risk management in the supply chain of telecommunication companies: a case study", Journal of Cleaner Production, Vol. 203 No. 1, pp. 53-67.

Wu, T. and Blackhurst, J.V. (Eds) (2009), Managing Supply Chain Risk and Vulnerability: Tools and Methods for Supply Chain Decision Makers, Springer Science and Business Media, New York, NY.

Xu, K., Tang, L.C., Xie, M., Ho, S.L. and Zhu, M.L. (2002), "Fuzzy assessment of FMEA for engine systems", Reliability Engineering and System Safety, Vol. 75 No. 1, pp. 17-29.

Zand Hessami, H. and Savoji, A. (2011), "Risk management in supply chain management", International Journal of Economics and Management Sciences, Vol. 1 No. 3, pp. 60-72.

\section{Corresponding author}

Sajjad Shokouhyar can be contacted at: s_shokouhyar@sbu.ac.ir
Supply chain sustainability risk analysis 
MSCRA

2,4

\section{0}

\section{Appendix}


$\sqrt{1}$
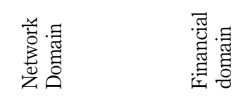

密瞢

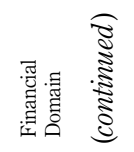



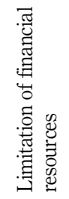



惫



㪯。

矛

$\stackrel{\leftrightarrow}{5}$

ษั

羿

ชุํำ

ปิ

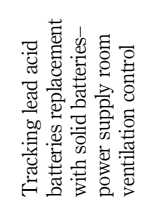

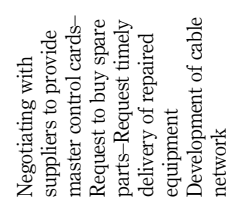

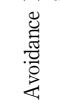

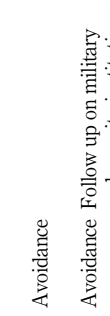

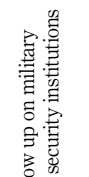

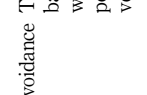

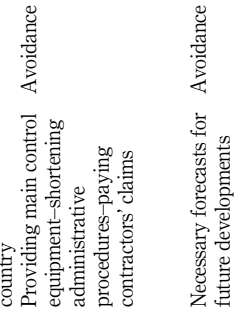

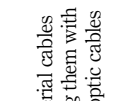

尊. 造

这密宽

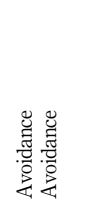

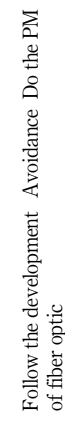

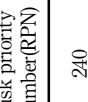

육

งิ

สู

고 옹

㞼 蛋

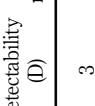

$\infty$
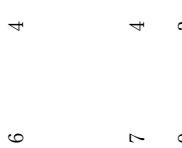

$\infty$

$\infty \infty$

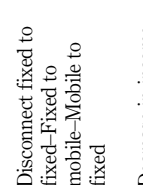

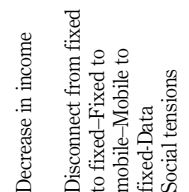

$\infty \infty \quad \infty$

氙

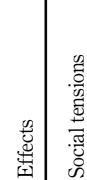

$\infty$

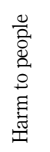

땠요

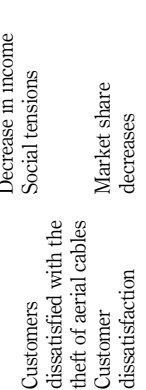

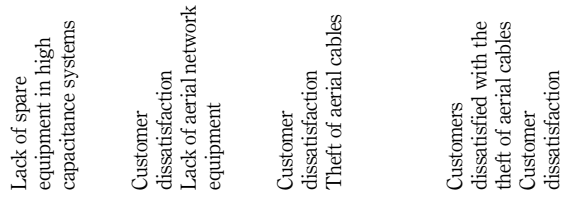




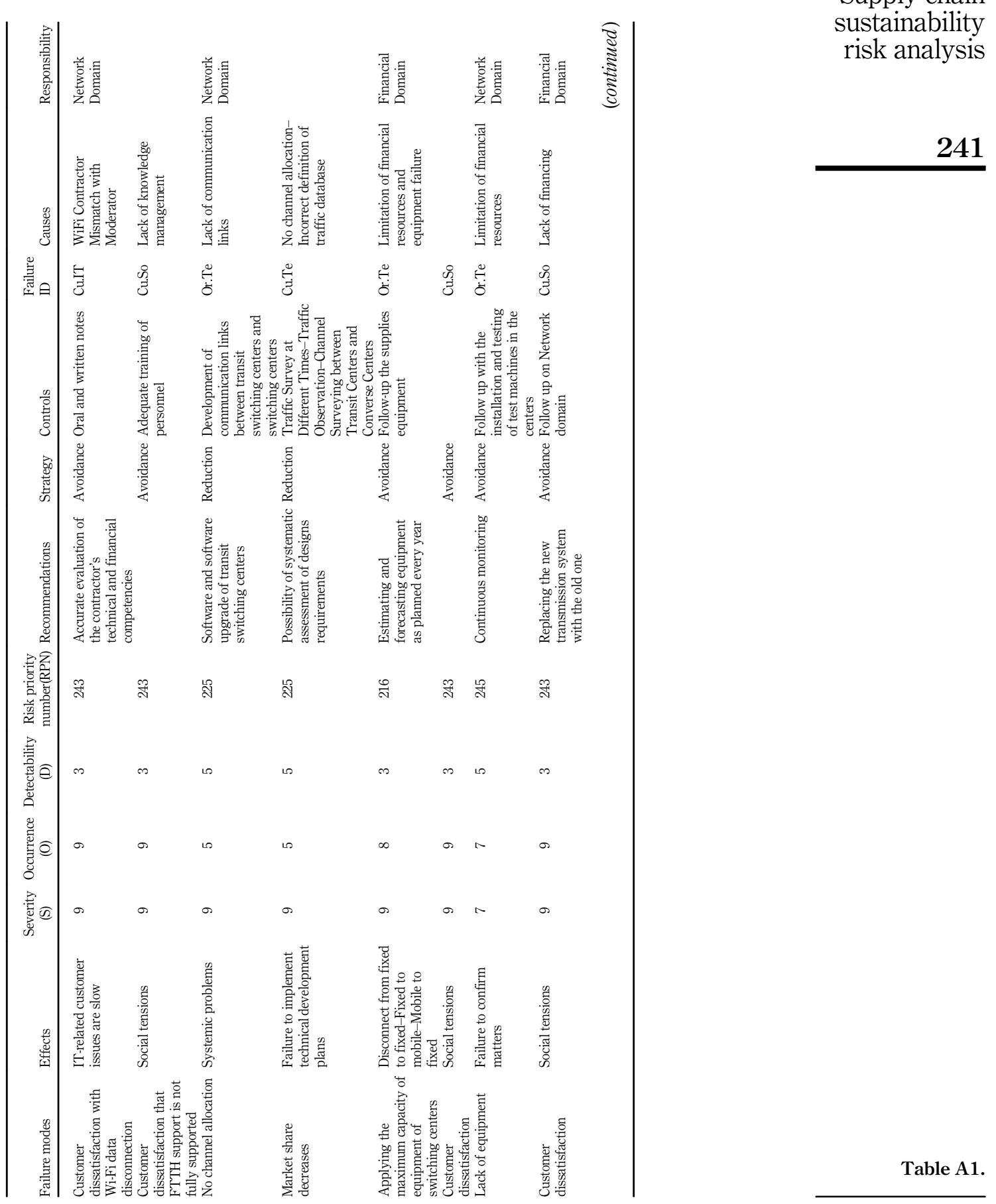


MSCRA

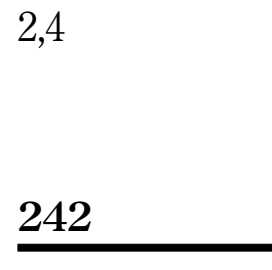

Table A1.

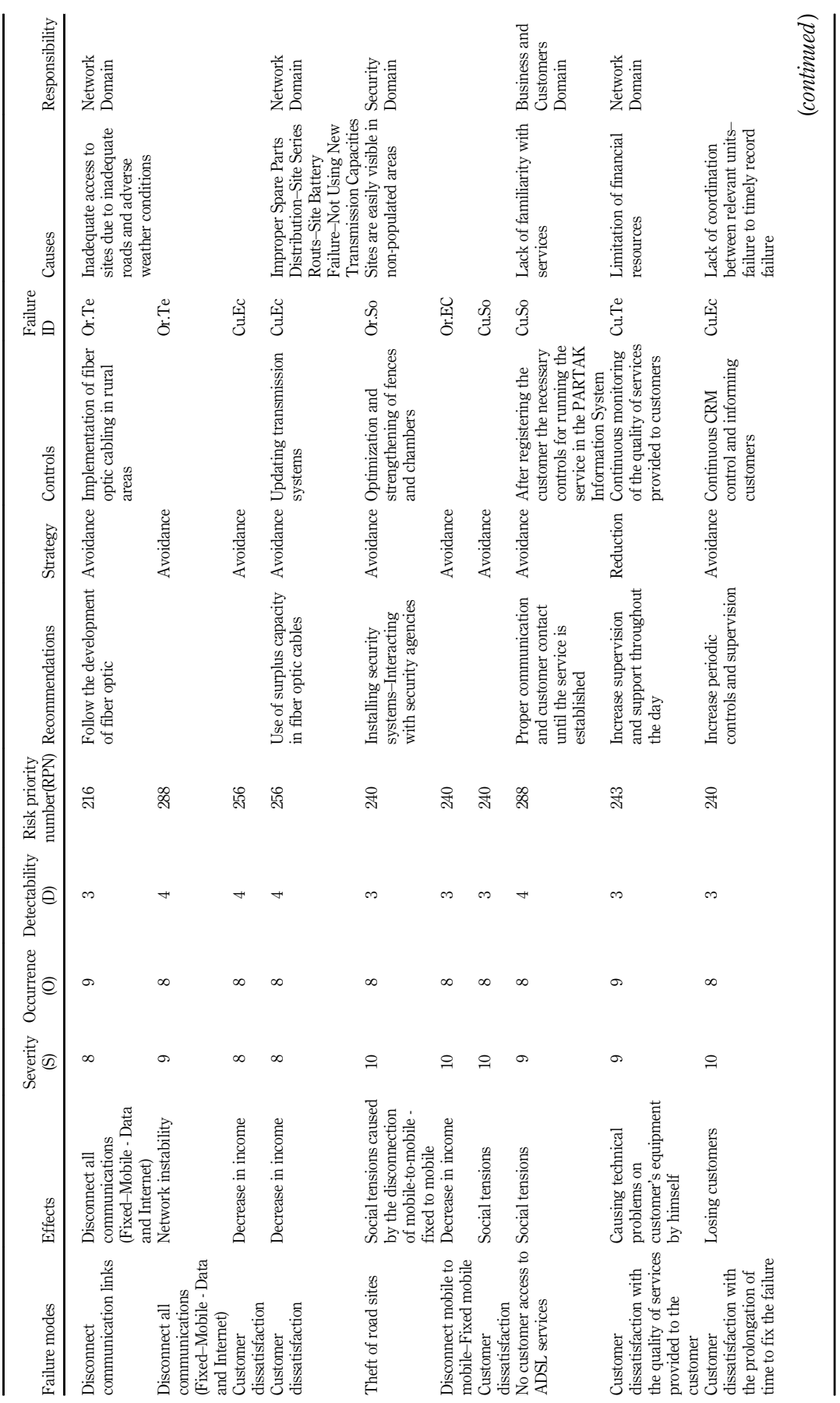






Supply chain

sustainability risk analysis

243

Table A1. 
MSCRA



\section{4}




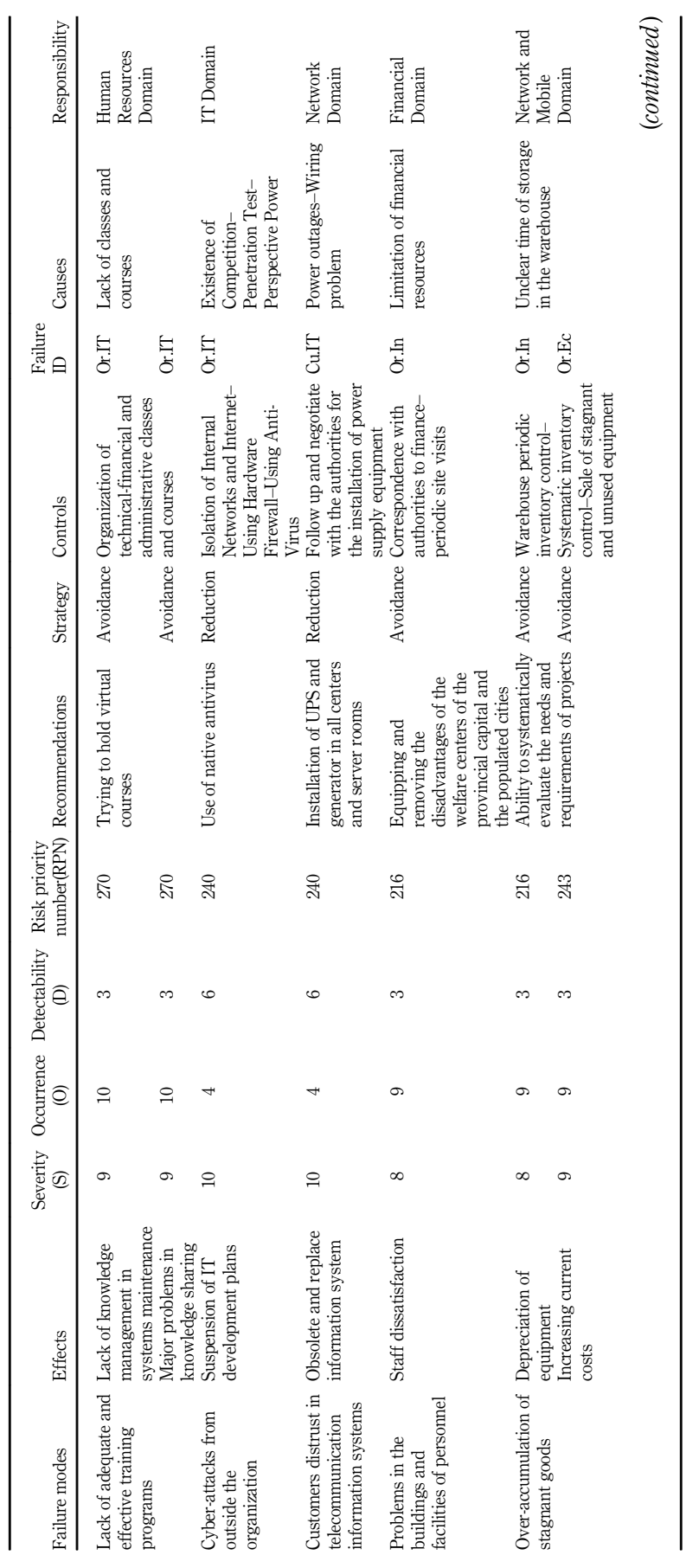

Supply chain sustainability risk analysis

245

Table A1. 
MSCRA

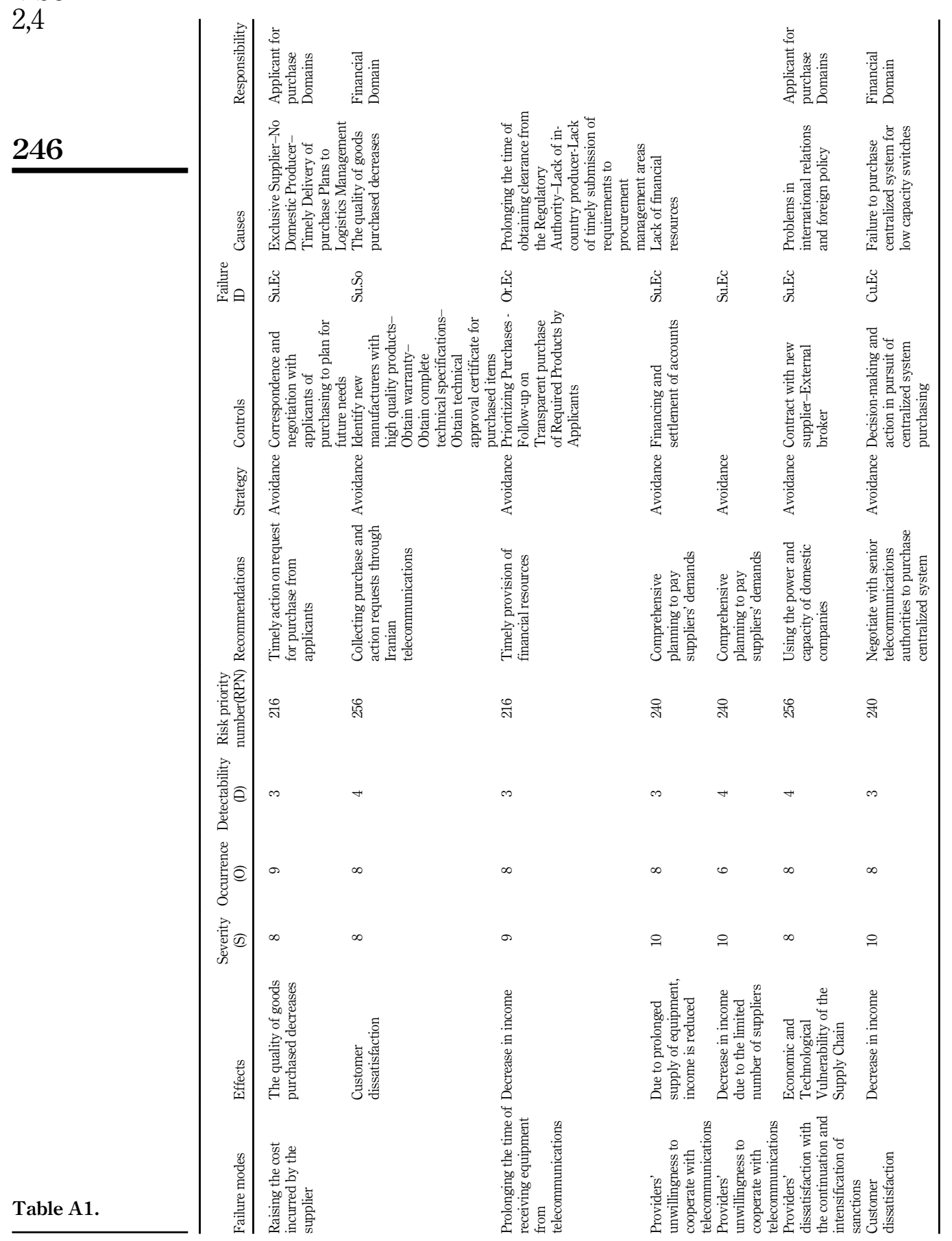

